Review

\title{
Oxidative Stress and the Homeodynamics of Iron Metabolism
}

\author{
Nikolaus Bresgen * and Peter M. Eckl \\ Department of Cell Biology, University of Salzburg, Hellbrunnerstrasse 34, 5020 Salzburg, Austria; \\ E-Mail: peter.eckl@sbg.ac.at \\ * Author to whom correspondence should be addressed; E-Mail: nikolaus.bresgen@sbg.ac.at; \\ Tel.: +43-662-8044-5776; Fax: +43-662-8044-144.
}

Academic Editor: Michael Breitenbach

Received: 31 December 2014 / Accepted: 22 April 2015 / Published: 11 May 2015

\begin{abstract}
Iron and oxygen share a delicate partnership since both are indispensable for survival, but if the partnership becomes inadequate, this may rapidly terminate life. Virtually all cell components are directly or indirectly affected by cellular iron metabolism, which represents a complex, redox-based machinery that is controlled by, and essential to, metabolic requirements. Under conditions of increased oxidative stress-i.e., enhanced formation of reactive oxygen species (ROS) - however, this machinery may turn into a potential threat, the continued requirement for iron promoting adverse reactions such as the iron/ $\mathrm{H}_{2} \mathrm{O}_{2}$-based formation of hydroxyl radicals, which exacerbate the initial pro-oxidant condition. This review will discuss the multifaceted homeodynamics of cellular iron management under normal conditions as well as in the context of oxidative stress.
\end{abstract}

Keywords: iron; oxidative stress; metabolism

\section{Systemic and Cellular Iron Transfers}

Ferric iron or iron contained in heme is absorbed by intestinal enterocytes via heme carrier proteins (HCP1) [1], the divalent metal transporter DMT1 (SLC11A2) [2,3] or the integrin-mobilferrin pathway [4,5] (a review on intestinal iron absorption is given in [6,7]). The absorbed iron is then released from the enterocytes to the bloodstream as transferrin-bound iron (TBI) via ferroportin (see below). Under physiological conditions, the bulk of iron enters the cell bound as TBI via transferrin-receptor (TfR) mediated endocytosis followed by endosomal iron liberation. However, resorption of non-transferrin 
bound iron (NTBI) from the bloodstream may also occur either via DMT-1, the zinc transporter Zip14 (SLC39A14) [8,9] or specific citrate binding sites [10-12]. Notably, the serum content of labile NTBI is very low under normal conditions but may rise substantially in diseased states, such as thalassemia, where the high NTBI level-essentially caused by repeated blood transfusion-is considered to cause disease-related oxidative stress [13-18]. Similarly, serum ferritin which may serve as iron carrier too $[19,20]$ and is also increased under certain pathological conditions, such as inflammation and cancer [21], can also be endocytosed [22-25] upon binding to distinct ferritin receptors [26-30], TIM-2 [31,32], Scara5 [33] as well as the TfR itself [34]. Finally, heme-bound iron will enter the cells via HCP1 [1] and tissue macrophages will also "ingest iron" upon phagocytosis of aged cells such as erythrocytes or via the haptoglobin/CD 163 or hemopexin/CD91 mediated uptake of hemoglobin or heme [35] and deliver the recycled iron back to the bloodstream, which is indispensable for the maintenance of systemic iron homeostasis [36].

In contrast to several ways of cellular iron uptake, only two mechanisms of cellular iron release are known. Usually, iron release from a cell occurs via ferroportin (Fpn) [37-41] a membrane bound iron exporter, which is controlled by hepatocyte derived hepcidin $[42,43]$, the hepcidin activity itself being regulated by the serine protease matriptase-2 $[44,45]$. The ferroportin-released iron is then directly transferred to transferrin by aid of the multi-copper ferroxidases hephaestin and caeruloplasmin [39,46-48]. Fpn-based iron release from enterocytes or macrophages is essential to systemic iron homeostasis, hepcidin acting as negative regulator of Fpn counteracting systemic iron overload [49]. Hypoxic conditions lower hepcidin expression and thus promote iron absorption [50,51], the negative regulation of hepcidin exerted by hypoxia inducible factor-1 [52] playing an important physiological role in the adaptation to increased altitudes [53]. Notably, apart from its role in systemic iron homeostasis, the Fpn-based iron release mimics the effect of iron chelators, such as desferrioxamine (DFO), by counteracting iron-based oxidative stress [54]. Supportive to this, reduced (or absent) ferroportin activity (e.g., upon hepcidin overexpression or mutation of the ferroportin gene) results in cellular iron overload [55,56]. Notably, mutation of the Fpn gene causes the so-called "ferroportin disease" - with symptoms of tissue iron overload reminiscent to hemochromatosis - however, at a less critical clinical manifestation [55]. In particular, unlike the hepatocytic iron overload seen in hemochromatosis, ferroportin disease patients show no hepatic iron accumulation. Noteworthy, serum ferritin levels increase in patients suffering from ferroportin disease [55], the secretion of iron loaded ferritin presumably protecting from hepatic iron overload.

Hence the relase of iron-loaded ferritin could represent a non-orthodox mechanism to avoid iron overload in cells that do not express Fpn or Fpn is inhibhited by high hepcidin levels which is also accompanied by increased serum ferritin levels [56]. The exact mechanism by which ferritin is secreted remains elusive, however, it has been shown that ferritin can be released via exocytosis in an iron dependent mode [57,58] and the release by secretory lysosomes has also been proposed [59]. Moreover, ferritin transcytosis has also been suggested [60]. Evidence exists that ferritin serves iron shuttling between cells including a presumptive role as iron transporter across "barriers" such as the blood-brain-barrier (BBB) or the placental brush border (PBB) $[19,26,29,61,62]$. The findings that uptake of extracellular ferritin may serve haemoglobin synthesis in erythroid precursor cells [24] and the use of ferritin (and not transferrin) as major iron source in oligodendrocytes [63] support this assumption. Furthermore, the ferritin content of serum correlates with total body iron stores $[21,64]$ and is increasing upon dietary iron supplementation [65] and also with age [66,67]. In addition, several 
diseased states are accompanied by pathological changes of serum ferritin levels such as anemia-based hypoferritinemia $[68,69]$ and the hyperferritinemia frequently associated with infection, inflammation and malignancy $[21,64,68,70,71]$, which potentially complicates serum ferritin-based assessment of the body iron status [72]. Albeit this points at a role of extracellular ferritin in cellular and systemic iron homeodynamics and evidence is increasing for a participation of serum ferritins in systemic stress responses (see Section 2.2), our understanding of the biological significance of ferritin secretion and uptake still is incomplete.

\section{Cellular Iron Compartmentalization}

Metabolic requirements focus on proper iron supply for the mitochondrial synthesis of heme and iron-sulfur (Fe-S) clusters, functional groups which are indispensable for cell function and serve as central determinants of cellular iron "handling". Conflicting with the strict demand for iron availability, free "labile", redox-active ferrous iron is prone to generate highly reactive ${ }^{\bullet} \mathrm{OH}$-radicals by reacting with $\mathrm{H}_{2} \mathrm{O}_{2}$ in the Fenton reaction eventually causing oxidative cell damage. Thus, intracellular iron is compartmentalized into distinct "cellular labile iron pools" which communicate via secure, protein-based iron shuttles (Figure 1).

Upon receptor-mediated endocytosis, iron will initially locate to the endo-/lysosomal compartment (ELC) from where it is forwarded to the cytosol via distinct iron transporters DMT-1, Zip14 or TRPML1 (mucolipin 1) [3,73-76]. With respect to the continuous need for iron, cytosolic ferritin will serve as dynamic iron buffer, which is essential to a steady-state of intracellular iron availability. Like ferroportin, ferritin will also counterbalance a transient iron overload by sequestering an excess of $\mathrm{Fe}^{2+}$ and thus confer antioxidant and cytoprotective functions [77,78]. However, most of the imported iron will be delivered immediately to the "users", in particular mitochondria, which may involve a bypass of cytosolic iron buffering (see below).

About $0.2 \%-5 \%$ of the total cellular iron is considered as transiently mobile, non-protein bound low molecular weight redox-active iron which together with chelatable protein-bound iron defines the dynamic, intracellular "labile" iron pool (LIP) encompassing compartment specific LIPs of the cytosol (CLIP - also including nuclear labile iron), the mitochondria (MLIP) and the endo-/lysosomal compartment (ELIP) in total containing about 6-16 $\mu \mathrm{M}$ iron, mainly as $\mathrm{Fe}^{2+}$ [79-84]. Iron is shuttled between these pools by several distinct mechanisms: (i) distinct donor-acceptor exchanges (e.g., iron uptake and release to and from ferritin); (ii) transfer of iron across membranes by iron transporters such as DMT-1, TRPML1, Zip14 (ELIP $\rightarrow$ CLIP); and (iii) iron "binding" to mitoferrin, paraferritin (see below) (CLIP $\rightarrow$ MLIP) and ferritin (CLIP $\rightarrow$ ELIP via autophagy) [79,85,86]. As mentioned, endosomal iron (ELIP) may also be transferred directly to mitochondria by a "kiss and run" mechanism, iron containing endosomes or iron containing vesicles docking to the outer mitochondrial membrane and passing the iron over to mitoferrin [87-91]. Notably, the latter mechanism circumvents the CLIP and allows an efficient direct transfer of iron to mitochondria which may be beneficial under physiologic conditions but could become critical under conditions of iron overload [90]. Transfers involving free ferrous iron represent a constant hazard of Fenton-reaction derived oxidative stress, which holds particularly true under conditions of iron overload and increased oxidative stress. 


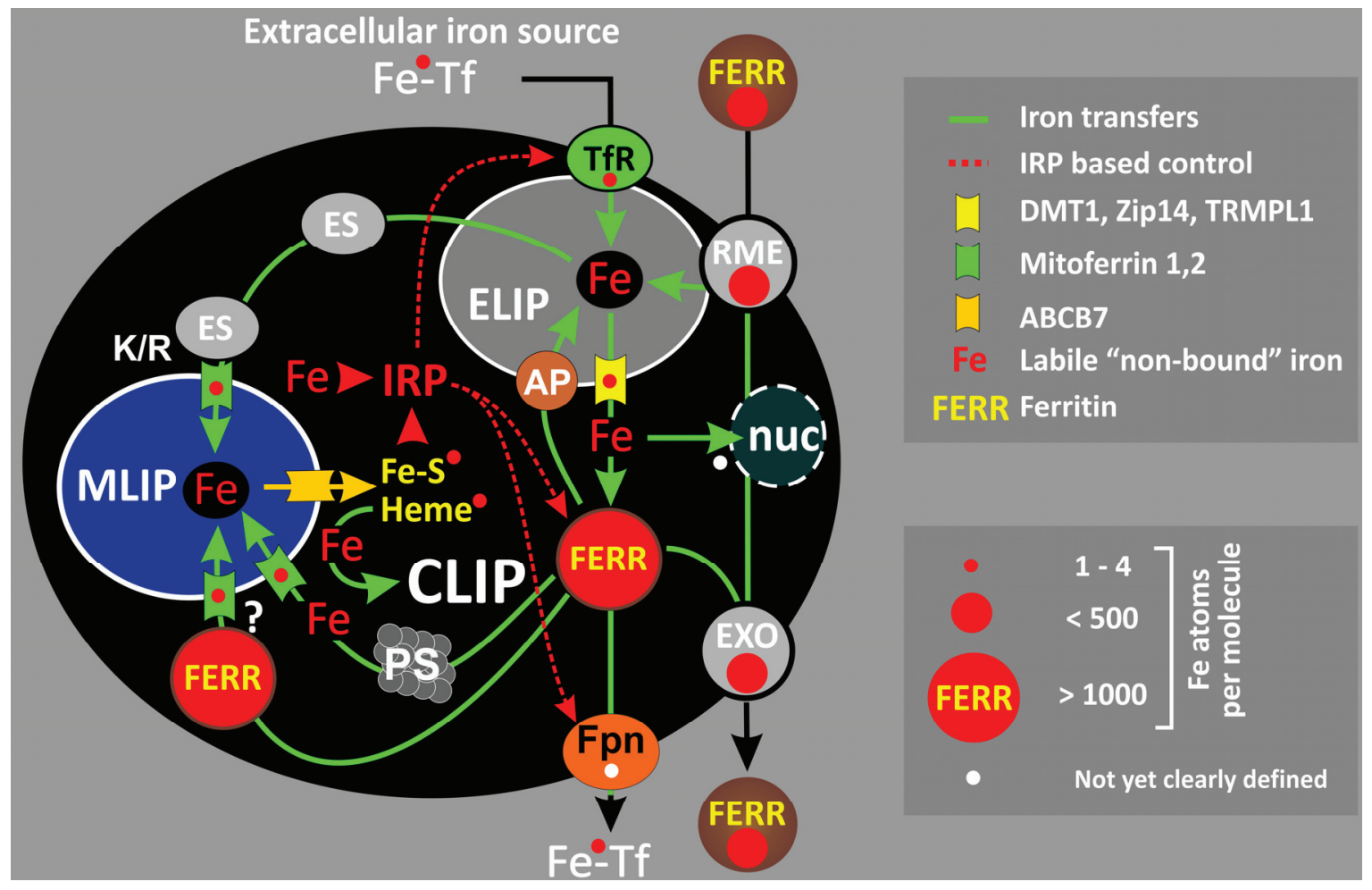

Figure 1. Cellular iron flux. Iron is transferred between communicating "labile iron pools" of the endo-/lysosomal system (ELIP), the cytosol (CLIP) and the mitochondria (MLIP). The ELIP represents the main entry site for extracellular iron such as transferrin bound iron (Fe-Tf) taken up via the TfR. Alternatively, iron containing serum ferritin may also enter the ELIP via receptor-mediated endocytosis (RME). Iron can exit from the ELIP via specific channels (DMT-1, Zip14, TRPML1) and is buffered in the cytosol (CLIP) by ferritin. Iron release from ferritin can occur via proteasomal degradation (PS) or lysosomal digestion upon autophagy (AP). Transfer of iron to the MLIP involves the iron transporter mitoferrin. The shuttling of "endosomal iron" (ES) to mitochondria by a "kiss and run" mechanism (K/R) as well as a hypothetical direct iron uptake from cytosolic ferritin has also been proposed. Note that iron can be buffered in the MLIP by mitochondrial ferritin. Ferroportin (Fpn) serves iron exit, the exact transfer mechanism not yet being resolved [39]. Fe-S clusters and heme, released from the mitochondria via $\mathrm{ABCB} 7$ transporter as well as labile, non-bound cytosolic iron serve as iron sensors for cytosolic IRPs. IRPs regulate the cellular labile iron pool via translational control of several iron-metabolism related proteins such as TfR, ferritin and ferroportin (Fpn). Alternative iron fluxes include heme-oxygenase 1 mediated iron liberation as well as ferritin endocytosis, transcytosis and exocytosis (EXO). The uptake of heme and extracellular NTBI is not shown. Red circles symbolize the relative iron binding capacities.

Lysosomal processing of iron loaded ferritin either upon autophagy or heterophagic uptake of "serum ferritin" represents such a situation where adequate coupling of the liberated ferrous iron to adequate acceptors is mandatory to avoid an excess of redox-active iron in the lysosomes. It has been shown that autophagy of apoferritin protects lysosomes from iron overload and exerts cytoprotective properties [92-94]. On the other hand, ferritin heterophagy may stimulate lysosomal stress and resulting growth adverse responses $[95,96]$. 


\subsection{Endo-/Lysosomal Iron-ELIP}

Intestinal iron absorption as by enterocytes occurs separately for $\mathrm{Fe}^{2+}$ and $\mathrm{Fe}^{3+}$ via the divalent iron transporter DMT-1, which also serves the uptake of ferrous NTBI in other cell types and the $\beta 3$-integrin-mobilferrin pathway [5]. $\beta 3$-integrin forms a large protein complex together with mobilferrin also incorporating DMT-1, which shows ferrireductase activity, and due to its size has been named paraferritin [97,98]. Intracellular paraferritin is considered to serve the shuttling of iron to mitochondria, which may also apply to iron derived from transferrin [6]. Different from this, iron adsorption of TBI occurs via TfR mediated endocytosis, the transferrin/TfR complex locating to the endosomal compartment where the acidic milieu supports the release of transferrin bound $\mathrm{Fe}^{3+}$. The iron-free apotransferrin/TfR complex is then recycled to the cell membrane where it dissociates, both components serving further iron acquisition. Inside the acidified endo-/lysosomal compartment, the liberated ferric iron is reduced to the ferrous state by the endosomal ferrireductase Steap3 [99,100], which is highly expressed in iron-rich cells, such as hepatocytes and macrophages [101]. The ferrous iron is then released from the endosomal compartment to the cytosol either via DMT-1 or the lysosomal iron channel TRPML1, a type IV mucolipidosis-associated protein also termed mucolipin-1 $[73,76]$. Interestingly, impaired TRPML1 function provokes a severe disturbance of cellular iron homeostasis, marked by cytosolic $\mathrm{Fe}^{2+}$ depletion and lysosomal $\mathrm{Fe}^{2+}$ overload, accompanied by the lysosomal accumulation of the indigestible lipid-protein oxidation product lipofuscin, sensitizing lysosomes to oxidative stress, which is causal to hereditary mucolipidosis and other lysosomal storage disorders involved in neurodegenerative diseases [73,102-105].

Notably, compared to transferrin which provides two iron ions $\left(\mathrm{Fe}^{3+}\right)$ per molecule, the uptake of serum ferritin via receptor mediated endocytosis expands the lysosomal labile iron pool more substantially since serum ferritins, albeit considered iron poor, may contain about $160-500 \mathrm{Fe}^{3+}$ ions per molecule [106,107]. Moreover, TfR-based iron import is regulated by cellular iron concentrations while this is not the case for the uptake of ferritin via asialoglycoprotein receptors [108]. Besides iron import from the environment, the lysosomal iron pool may also expand upon organelle recycling by macroautophagy of iron-rich mitochondria (mitophagy) and peroxisomes (pexophagy) as well as lysosome recycling itself [109-112], which represents a particularly critical issue during damage induced reparative autophagy [113,114]. Furthermore, macroautophagy of cytosolic iron-loaded ferritin and iron liberation by lysosomal processing will also expand the ELIP [115].

With respect to the different iron input routes feeding the ELIP, iron release from the lysosome is pivotal to the maintenance of proper levels of lysosomal labile iron. Moreover, the pathogenic effect of TRPML1 failure emphasizes the necessity for a stringent ELIP control, especially in post-mitotic cells such as neurons. Several reports have shown the dependence of lysosomal stability on lysosomal iron load $[92,94,116-120]$. Critical to this, the $\mathrm{Fe}^{2+}$-based ${ }^{\bullet} \mathrm{OH}$ formation is fostered by pro-oxidant conditions, which stimulates lysosomal lipid peroxidation and consequently increases the susceptibility to lysosomal membrane permeability (LMP) and subsequent cell death [117,118,121-128]. Evidence is increasing that cells are able to antagonize lysosomal iron overload and the oxidative stress derived thereof by transferring antioxidants, including apoferritin, to the ELC by macroautophagy $[93,94,129]$. Moreover, the pro-oxidant conditions arising from LMP have a stimulatory effect on de novo ferritin synthesis $[94,130]$. 
Summarizing, the dynamics of the ELIP serve as "rheostat" of cellular iron flux, which in context with the pro-/antioxidant balance couples redox control to lysosome stability and cell integrity.

\subsection{Ferritin-CLIP}

As stated above, ferritin-based iron-buffering is crucial to cellular integrity in particular under conditions of increased oxidative stress. Albeit ferritin has a maximum storage capacity of $4500 \mathrm{Fe}^{3+}$ ions per ferritin molecule [78], biological ferritin samples may contain less iron $\left(<2000 \mathrm{Fe}^{3+} /\right.$ ferritin molecule), which holds particularly true for secreted, serum ferritins as already stated [106,107,131]. Ferritin is a multimeric protein with a molecular weight of about $450 \mathrm{kDa}$, composed of 24 heavy ( $\mathrm{H}$ chain of 21-23 kDa) and light (L chain of 19-21 kDa) subunits arranged in a hollow sphere conformation [132]. Several tissues-specific isoforms have been described which vary in the H:L chain ratio and with respect to their pI are classified as basic, L-rich (e.g., liver, spleen) or acidic, H-rich (e.g., muscle, heart, brain) isoferritins [132-134].

Contrasting the low sequence homology (in mammalians about $\sim 54 \%$ ), the ferritin $\mathrm{L}$ and $\mathrm{H}$ chain show a remarkably high conformational homology [132]. Iron enters the ferritin molecule in the ferrous state via three-fold channels. The entrance is facilitated by the chaperone PCBP1 (Poly-r(C)-Binding Protein 1) [135] and involves oxidation by the ferroxidase activity of the $\mathrm{H}$-chain, a process which also consumes $\mathrm{H}_{2} \mathrm{O}_{2}[132,136]$. The oxidized iron is then shuttled to the inner cavity of the ferritin molecule where it is stored in a mineralized form, the nucleation process aided by the L-chain $[137,138]$. Iron exit from ferritin (recently reviewed in [139]) involves the reduction of the mineralized $\mathrm{Fe}^{3+}$, however, may also involve electron transfers, gated pores as well as direct iron release mechanisms, which are not based on reduction (reviewed in [140]). Small reducing molecules such as $\mathrm{O}_{2}{ }^{\bullet-}$, ascorbate or the ascorbate radical [132] and $\mathrm{NO}^{\bullet}$ (see below), but also sulfide [141] and hydroxydopamine (6-OHDA) [142] are able to mobilize iron from intact ferritin in vitro. Ionizing radiation together with ascorbate may also trigger $\mathrm{O}_{2}{ }^{\bullet-}$-dependent iron release which expands the LIP in post mortem tumor tissue [143]. Ferritin degradation appears to play an important role in iron release from ferritin in vivo [144-147], which can be stimulated by iron chelators [148] and oxidative stress [149]. Notably, while iron chelators stimulate autophagy and lysosomal ferritin processing, iron release triggered by ferroportin precedes proteasomal digest of the "iron-depleted" ferritin [42,145,148]. Thus, iron liberation from ferritin may follow different context-dependent routes serving either cellular iron release (proteasome) or the refueling of a rapidly emptied CLIP (autophagy/ELC). Considering the above discussed risk of lysosomal destabilization arising from ferritin autophagy in oxidatively stressed cells, CLIP depletion under prooxidant conditions will become a potent, cytotoxic challenge when the cell is not adequately equipped with antioxidants including newly synthesized apoferritin.

Emphasizing the antioxidant properties of ferritin, overexpression of human H-chain ferritin confers solid protection against oxidative stress [136]. It has been shown that iron mediated lipid peroxidation is suppressed by recombinant $\mathrm{H}$ and $\mathrm{L}$ ferritins in vitro, which requires both the ferroxidase as well as iron mineralization activity [150]. While L-chain rich isoforms stably incorporate iron at increased cellular iron levels [151], the higher ferroxidase activity of $\mathrm{H}$ chain-rich ferritins allows a faster and more efficient iron sequestration, which also improves the antioxidant and cyto-protective potential under conditions of oxidative stress $[78,132,152]$. Thus, with respect to the coordinated regulation of 
iron oxidation and iron storage, the ferritin H:L ratio plays an important role in tissue specific iron regulation and antioxidant defenses [152], which probably affects the aging process too since the life-span in Saccharomyces cerevisiae and Caenorhabditis elegans is extended upon (over)expression of the human ferritin L-chain [153].

Cellular ferritin levels are regulated primarily at the translational level via m-RNA binding proteins IRP-1 and IRP-2 described below. Nevertheless, the genes for the ferritin H and L chain contain binding sites for $\mathrm{NF}-\mathrm{\kappa B} / \mathrm{Rel}$ and elements with similarity to AP-1, which mediate transcriptional control of the H-chain by the oncogenes c-Jun and c-Fos [154,155]. Moreover, antioxidant response elements (ARE) located in the promoter region of both ferritin genes allow binding of Nrf2 and junD [156-158], which also links transcriptional control of ferritin to cellular stress management. Thus, ferritin synthesis can be regulated in an iron independent mode for instance by inflammatory cytokines (e.g., TNF- $\alpha$, IFN $\gamma$, IL-1 $\beta$, IL-6 - preferentially stimulating H-chain expression) and oxidative stress, which confers cytoprotection [58,159-169]. Strikingly, p53 affects ferritin synthesis too either as negative regulator on the transcriptional level supposedly weakening cellular antioxidant defense in favor of promoting apoptosis [170] or by upregulating ferritin biosynthesis which supports cell survival due to an increased iron sequestration [171]. In addition, experimental evidence exists that the iron controlled synthesis of the ferritin $\mathrm{H}$ and $\mathrm{L}$ chain occurs independently of each other and is modulated by cellular oxygen levels at the transcriptional as well as translational level [172-176]. Hence, ferritin synthesis is regulated by multiple elements of transcriptional and translational control, which supports a tight, dynamic linkage of iron buffering and the oxidant balance to cell cycle and cell death control.

The stimulation of ferritin synthesis by inflammatory cytokines can be paralleled by enhanced ferritin secretion [58]. In accordance with this, serum ferritin levels are increased in inflammatory contexts rendering ferritin an acute phase reactant [177-181]. It is assumed that this elevation of serum ferritin counteracts iron mediated oxidative stress in the inflamed tissue and, in the case of bacterial infection, probably also limits iron availability for bacterial growth [159,177,178,180,182]. Since proinflammatory cytokines preferentially promote ferritin H-chain expression [169], acute phase associated serum ferritins likely represent H-chain rich isoforms [180] which differ from the L-type ferritin found in serum under normal conditions [21]. Therefore, the inflammation related switch towards $\mathrm{H}$ chain-rich serum ferritins which reveal an improved antioxidant activity corresponds well with the enhanced synthesis of $H$ chain-rich, cyto-protective ferritin in oxidatively stressed cells [136,173]. Hence, similar to ferritin mediated iron buffering in the CLIP, ferritin secretion may expand systemic iron buffering capacity in particular under pro-oxidant conditions.

Finally, it should not be neglected that heme-containing proteins, despite the minimal iron binding capacity of protoporphyrin, also affect cellular iron homeodynamics. While heme-biosynthesis lowers the MLIP (discussed in the next section) [183], heme-degradation by heme-oxygenase I (HO-I) [184] potentially adds iron to the CLIP which may occur in the cytosol but alternatively could also locate to the ELIP in macrophages following erythrocyte phagocytosis $[185,186]$. Free heme sensitizes cells for cell death especially under pro-inflammatory, pro-oxidant conditions in an iron dependent mode [187-189]. Thus, heme degradation by HO-I will confer cyto-protection provided the released iron is efficiently sequestered by ferritin [190]. In line with this, HO-I and ferritin are concomitantly upregulated in cells exposed to oxidative stress [191,192], and cytosolic iron overload caused by 
an excessive, HO-I-based heme-degradation such as seen in malaria may also be antagonized by the up-regulation of H-ferritin [193].

\subsection{The Mitochondrial Iron Pool-MLIP}

Complementary to ELC and ferritin-based iron handling, proper mitochondrial iron homeostasis is indispensable for cellular iron management in particular by controlling the synthesis of heme and Fe-S clusters [194-197], functional groups which are essential to the functionality of numerous proteins including those participating in energy production via the respiratory chain. Intimately connected with this, the MLIP also affects the synthesis of Fe-S cluster containing iron regulatory protein-1 (IRP-1) and by this directly interferes with IRP-based translational control of proteins involved in iron management, in particular ferritin, the transferrin receptor, ferroportin and DMT-1. Thus, the iron flux between the CLIP and the MLIP has to be tightly coordinated and is also regulated by a feedback mechanism based on Fe-S cluster synthesis and IRP-1 activity. The MLIP is fueled from the CLIP as well as directly from the ELIP as explained above. Albeit the knowledge on iron shuttling across the outer mitochondrial membrane is still incomplete, the endosomal supply via a "kiss and run" mechanism could involve a distinct endosome-mitochondria interaction and the existence of specific mitochondrial ferritin binding sites has been proposed too [85,198]. In contrast, it has been demonstrated that the iron transfer across the inner mitochondrial membrane is mediated by the mitochondrial iron carrier mitoferrin 1,2 (Mfr1,2) [87,199,200], which may involve the regulation via Mfr protein stability as suggested by the interaction of Mfr1 with the mitochondrial inner membrane ATP-binding cassette transporter Abcb19 in erythroblasts [201]. Notably, Mfr1 and 2 are not regulated by IRPs but other cis-acting elements [202]. Whatever mechanism is responsible for mitochondrial iron uptake, it has to be strictly controlled since any disturbance of the MLIP will critically affect cellular iron management. This is exemplified by pathological conditions caused by mitochondrial iron mismanagement including Friedreich's Ataxia (caused by frataxin deficiency — see below), erythropoietic protoporphyria (a disorder marked by ferrochelatase deficiency and impaired heme synthesis) or sideroblastic anemia (where disrupted heme synthesis alters mitochondrial ferritin levels, the enriched mitochondria resulting in ringed sideroblasts) reviewed in [203-206].

Of special relevance, an expansion of the MLIP will also occur when Fe-S clusters (e.g., contained in mitochondrial dehydratases such as aconitase) are oxidized by superoxide $\left(\mathrm{O}_{2}{ }^{\bullet-}\right)$ formed upon electron leakage from the respiratory chain (reviewed in [207]). Moreover, albeit mitochondrial superoxide dismutase (MnSOD) will detoxify $\mathrm{O}_{2} \bullet$, the dismutase reaction will generate $\mathrm{H}_{2} \mathrm{O}_{2}$, which readily reacts with "labile" ferrous iron leading to the generation of $\bullet \mathrm{OH}$ radicals and subsequent lipid peroxidation in the mitochondrial compartment. Notably, cytochrome c oxidase which catalyzes the electron transfer in complex IV of the respiratory chain is inhibited by the lipid peroxidation product 4-hydroxy-nonenal (HNE) [208]. Thus an expanded MLIP at inadequate antioxidant defenses will promote mitochondrial damage with severe consequences. Indeed, Halliwell (1992) has pointed at this adverse effect of SOD-activity, which may occur under certain pathologic conditions [209]. Therefore, the MLIP has to be maintained at an optimum balance which sufficiently serves metabolic needs but does not "fuel" Fenton reaction-based oxidative damage. Moreover, degradation of iron overloaded, damaged 
mitochondria in autophagolysosomes will amplify the effect of mitochondrial oxidative stress by stimulating lysosomal iron overload as illustrated above [210,211].

It has to be noted that no distinct iron exporter has been identified in mitochondria, the release of newly synthesized heme and Fe-S clusters to the cytosol representing the only way that the MLIP can be lowered. Fe-S clusters are transferred by mitochondrial ATP-binding cassette proteins Atm1, $\mathrm{ABC}$ protein 3 and $\mathrm{ABCB} 7$ (the human ortholog of yeast Atm1), which has been shown to counteract mitochondrial iron overload [212-215]. Correspondingly, deficiency of such proteins will increase the MLIP, which has been shown for yeast Atm1 raising the mitochondrial iron content by about 30-fold [216] and also holds true for ABCB7 deficiency in humans causing the rare hereditary disease X-linked sideroblastic anemia and ataxia (XLSA/A) [214,217]. The way that heme is transported to the cytosol remains to be clarified; however, the involvement of a heme-carrier protein, such as heme binding protein-1 (p22 HBP), has been suggested [87,218]. The lack of distinct iron exporters emphasizes the mitochondrial compartment as "bottleneck in iron metabolism" the incoming iron being either directly consumed for Fe-S cluster- and heme synthesis or stored in mitochondria-resident proteins, such as mitochondrial ferritin (see below).

\subsection{Mitochondrial Iron Usage_Frataxin and Mitochondrial Ferritin}

Frataxin (Ftx; Yfhlp in yeast; CyaY in bacteria; reviewed in [219,220]) represents an iron binding protein of high relevance to mitochondrial function and integrity. Ftx can form multimeric complexes of different size, which can bind between 50-3000 iron ions (depending on the species and grade of multimerization) in its ferric state, although the iron binding capacity of Ftx may be much lower in vivo [221,222]. Opposite to ferritin, which is synthesized as iron-free apoferritin, assembly of Ftx multimers depends on iron [221].

Ftx has gained substantial interest over the last decade since mutations of the Ftx gene are causal to the autosomal recessive disease Friedreich's Ataxia (FRDA) [205,206,223,224], most patients showing strongly reduced levels of Ftx mRNA [223,225] and protein [226]. The disease is marked by severe neurological manifestation, as well as pathological changes of the skeleton (scoliosis), pancreas (diabetes mellitus) and heart. In fact, cardiomyopathy and cachexia represent the most frequent cause of death in FRDA patients; for a detailed review on FRDA see [205] and recent advances in Ftx research are compiled in [219]. From the biochemical point of view, FRDA is marked by iron accumulation and lipofuscin deposits [227]. In particular, FRDA is accompanied by a reduced content of mitochondrial Fe-S cluster containing proteins and a loss of aconitase activity [228], which points at the primary function of Ftx, acting as "iron chaperone" in providing iron for the scaffold protein ISCU (iron-sulfur cluster forming unit) which is essential to mitochondrial Fe-S cluster biosynthesis [229-231]. Ftx also serves the transfer of iron to mitochondrial membrane associated ferrochelatase [232], a Fe-S cluster containing protein which catalyzes the final step of heme biosynthesis, the transfer of iron to protoporphyrin IX [233,234].

Albeit Ftx primarily serves ISCU formation, further functions include mitochondrial iron trafficking as well as mitochondrial redox and ROS control [87,235]. Ftx-deletion in fibroblasts yields a characteristic cellular FRDA phenotype, including mitochondrial iron deposits, reduced Fe-S enzyme activity and degenerating mitochondria [229]. Also, neurons of Prp-CreER ${ }^{\mathrm{T}}$ mice, a mouse model for FRDA, 
show aberrant autophagy, large vacuoles and lipofuscin accumulation [236]. Notably, malfunctioning mitochondria are recycled by mitophagy, which promotes lipofuscinogenesis and renders lysosomes unstable when occurring in excess [237,238]. Hence, Ftx-deficiency may also hamper ELC function and the autophagic process. Pointing at secondary effects of Ftx deficiency in FRDA, markers for lipid peroxidation (malondialdehyde) and oxidative damage (8-hydroxy-2'-deoxyguanosine) are increased in urine and blood of FRDA patients [239-241]. This indicates the onset of iron derived, free radical-based oxidant events upon loss of Ftx activity which may be detrimental to mitochondrial function and will also affect the whole cell. In fact, Ftx deficiency can promote ROS generation in mitochondria (i.e., formation of ${ }^{\bullet} \mathrm{OH}$ by the Fenton reaction), which is accompanied by oxidative mitochondrial damage and the upregulation of ferritin gene expression via nitric oxide (NO) signaling [242,243]. Furthermore, Ftx deficiency also sensitizes cells to oxidative stress $[239,244]$, which may involve both mitochondria and the ELC as discussed above. Taken together, Ftx represents an important regulator of mitochondrial and cellular iron homeodynamics in particular under conditions of iron overload and oxidative stress. It is tempting to consider Ftx as mitochondrial iron buffer, which similar to cytosolic ferritin provides "antioxidant" properties. However, different from the yeast Ftx knock-out mutant $\Delta$ Yfh1 [245] and Ftx-deleted mammalian cells, mitochondrial iron deposits have neither been found in FRDA patients [246] nor in Ftx-deficient Prp-CreER ${ }^{\mathrm{T}}$ mice [247]. Also, Ftx oligomerization is not critical to Ftx function in vivo [229]. Hence, Ftx may not serve MLIP iron buffering in vivo [246,248], but support cell integrity and iron homeodynamics by its participation in ISCU/Fe-S assembly for IRP-1 synthesis.

Another mitochondrial iron binding protein - mitochondrial ferritin (mtFER) - was discovered about a decade ago [249] (reviewed in [250]). mtFer, encoded by an intronless gene shows homology to H-ferritin and also bears a ferroxidase center [251]. Albeit mtFER ferroxidase activity and iron uptake kinetics show some differences to cytosolic ferritins, mtFER is also arranged as 24-subunit homopolymer, which efficiently oxidizes and sequesters ferrous iron [252,253]. In contrast to cytosolic ferritin, however, translation of mtFER is not under the control of iron since the mtFER-mRNA lacks iron regulatory elements (IRE), the 5' UTR being mutated to a leader sequence which mediates mitochondrial targeting [249]. Also different from cytosolic ferritin, mtFER-mRNA has been found at high abundance only in testis and spermatozoa, lower amounts in the brain, kidneys, pancreas (islets of Langerhans) and thymus but is absent from tissues with high iron storage function such as liver and spleen $[249,251,254]$. Of pathological relevance, mtFER is increased in erythroblast mitochondria of patients suffering from sideroblastic anemia [203] an erythrocyte phenotype (ring sideroblasts), which is also found in XLSA/A patients, caused by ABCB7 deficiency-based mitochondrial iron accumulation (see above). Although the exact role of $\mathrm{mtFER}$ in iron metabolism remains to be defined in detail it has been shown that overexpression of mtFER in tumor cells leads to iron relocation from the cytosol to the mitochondria provoking mitochondrial iron accumulation and cytosolic iron depletion which abrogates ferritin synthesis and stimulates TfR production [254-256]. Overexpression of $\mathrm{mtFer}$ in tumor cells also modulates cellular ROS levels and-like Ftx deficiency-increases the sensitivity to oxidative stress leading to the onset of apoptosis. Notably, this "toxic" effect of mtFER overexpression is considered to result from increased lysosomal degradation of iron overloaded mitochondria which leads to a shift of redox-active iron in the lysosomes, oxidative stress and the enhanced consumption of antioxidants [257,258]. Furthermore, mtFER as well as cytosolic ferritin containing deposits are 
found in mitochondria of Ftx-deficient cardiomyocytes of FRDA patients, which points at the role of iron/ferritin derived mitochondrial damage in cardiomyocyte cell death [259]. On the contrary, enhanced expression of mtFER may also rescue Yfhl deficient yeast cells as well as Ftx deficient Hela cells from mitochondrial dysfunction and confer protection from iron mediated oxidative injury [260-262].

Based on this, it is obvious that mitochondrial iron binding proteins by representing "guardians" of the MLIP provide an essential control of general, cellular integrity. It cannot be ruled out that endocytosed ferritin is transferred to the ELC and ferritin containing endosomes may also directly attach to mitochondria according to a "kiss and run" mechanism providing iron to the mitochondria as suggested by Ulvik [85]. If so, the interaction of internalized ferritin with mitochondria would likely result in the same outcome as seen upon mtFER overexpression: enhanced oxidative stress and free radical-based organelle damage, which eventually triggers apoptotic cell death.

\section{Iron Regulatory Proteins (IRP-1, IRP-2)}

\subsection{IRP-1: Redox-Based Control of Cellular Iron Homeodynamics}

Several proteins which show redox-based properties contain Fe-S clusters of the types [4Fe-4S], $[3 \mathrm{Fe}-4 \mathrm{~S}]$ and $[2 \mathrm{Fe}-2 \mathrm{~S}]$. For example, these include ferrochelatase, ferredoxin (providing electron transfer for cytochrome P-450 activity), aldehyde oxidase 1 (AOX1), xanthine dehydrogenase/xanthine oxidase, glutaredoxin 2 (a GSH-dependent oxidoreductase), nuclear proteins involved in DNA and RNA metabolism and DNA repair, and proteins of the mitochondrial respiratory chain participating in the assembly of the electrochemical gradient [263] (a recent review on the sensory and regulatory functions of Fe-S proteins is given in [264]). Of special relevance, Fe-S cluster bearing iron regulatory protein 1 (IRP-1) exerts a dual function. In the presence of "iron replete" [4Fe-4S] clusters, IRP-1 shows cytosolic aconitase activity (c-aconitase; ACO1) catalyzing the citrate to isocitrate interconversion in the cytosol, which regulates cellular NADPH levels $[265,266]$. However, low cytosolic iron levels as well as pro-oxidant regimens promote cluster disassembly, which abolishes c-aconitase activity but uncovers IRP-1 mRNA binding properties [265]. IRP-1 binds with high affinity to IREs marked by a stem-loop located at the 5' and 3' UTR of mRNAs encoding iron-regulatory proteins, in particular ferritin and Fpn (5' UTR located IRE) as well as TfR, DMT-1 and eALAS (erythroid 5-aminolevulinate synthase producing the heme precursor 5-aminolaevulinic acid) with an IRE at the 3' UTR [267,268]. Hence, the Fe-S cluster dependent control of IRP-1 activity serves as redox-active iron sensor which links translational control to cellular iron homeodynamics. Importantly, the Fe-S cluster-based IRP-1/IRE interaction either represses or induces translation of the target mRNAs, thus allowing a precise, efficient control of intracellular iron fluxes: CLIP depletion will favor cluster disassembly and promote IRP-1 RNA binding which inhibits ferritin (and ferroportin) synthesis but triggers TfR (and DMT-1) synthesis resulting in enhanced iron uptake and limited iron sequestration [269]. At increased iron levels, IRP-1 RNA binding activity declines, the IRE release allowing enhanced iron buffering and limited iron influx.

Hence, the continuous control of cellular iron fluxes by the specific IRP-1 activity participates in ELIP, CLIP, and indirectly also MLIP iron balance. Notably, the fact that Fe-S clusters are synthesized in the mitochondria emphasizes the significance of the MLIP to cellular iron homeodynamics. Indeed, 
Fe-S clusters may report iron loading of the MLIP since a hindrance of Fe-S cluster synthesis due to ISCU inactivation excessively shifts iron transfer to mitochondria which depletes the CLIP and increases IRP-1 RNA binding activity resulting in a disturbance of cellular iron homeodynamics [270].

\subsection{Fe-S Cluster Oxidation}

IRP-1 activity is modulated by ROS, which modify Fe-S cluster conformation, including cluster destabilization, and can also lead to IRP-1 degradation, connecting iron management and metabolic activity to cellular ROS production [271-275]. Oxidation of [4Fe-4S] clusters by $\mathrm{O}_{2}{ }^{\bullet-}$ and $\mathrm{H}_{2} \mathrm{O}_{2}$ yields the [3Fe-4S]-IRP-1 conformation, which lacks aconitase activity (Equations (1) and (3)), the reuptake of $\mathrm{Fe}^{2+}$ restoring the [4Fe-4S]-IRP conformation (Equation (4)) and aconitase activity, which is supported by sulfhydryls such as glutathione (GSH) (Equation (5)) [273,276-279].

$$
\begin{aligned}
& {[4 \mathrm{Fe}-4 \mathrm{~S}]^{2+}+\mathbf{O}_{2}{ }^{--}+2 \mathrm{H}^{+} } \rightarrow[3 \mathrm{Fe}-4 \mathrm{~S}]^{+}+\mathbf{F e}^{2+}+\mathbf{H}_{2} \mathbf{O}_{2} \\
& {[4 \mathrm{Fe}-4 \mathrm{~S}]^{2+}+\mathbf{H}_{2} \mathbf{O}_{2} } \rightarrow[4 \mathrm{Fe}-4 \mathrm{~S}]^{3+}+\mathrm{OH}^{-}+\mathbf{O H} \\
& {[4 \mathrm{Fe}-4 \mathrm{~S}]^{3+} } \rightarrow[3 \mathrm{Fe}-4 \mathrm{~S}]^{+}+\mathbf{F e}^{2+} \\
& {[3 \mathrm{Fe}-4 \mathrm{~S}]^{+}+\mathrm{e}^{-} \rightarrow[3 \mathrm{Fe}-4 \mathrm{~S}]^{\circ}+\mathrm{Fe}^{2+} \rightarrow[4 \mathrm{Fe}-4 \mathrm{~S}]^{2+} } \\
& {[3 \mathrm{Fe}-4 \mathrm{~S}]^{+}+\mathrm{Fe}^{2+}+\mathrm{GSH} \rightarrow[4 \mathrm{Fe}-4 \mathrm{~S}]^{2+}+1 / 2 \mathrm{GSSG}+\mathrm{H}^{+} } \\
& {[4 \mathrm{Fe}-4 \mathrm{~S}]^{2+}+\mathbf{H}_{2} \mathbf{O}_{2} } \rightarrow\left[4 \mathbf{F e}-4 \mathrm{~S} / \mathbf{O}^{2+}+\mathrm{H}_{2} \mathrm{O}\right. \\
& {[4 \mathrm{Fe}-4 \mathrm{~S} / \mathrm{O}]^{2+}+\mathrm{H}^{+} \rightarrow[3 \mathrm{Fe}-4 \mathrm{~S}]^{+}+\mathrm{Fe}^{3+}+\mathrm{OH}^{-} } \\
& \mathrm{Fe}^{2+}+\mathbf{H}_{2} \mathbf{O}_{2} \rightarrow \mathrm{Fe}^{3+}+\mathrm{OH}^{-}+\mathbf{O H}^{-}
\end{aligned}
$$

Notably, albeit cluster oxidation by $\mathrm{H}_{2} \mathrm{O}_{2}$ could theoretically generate ${ }^{\bullet} \mathrm{OH}$ radicals (Equation (2)), it is more likely that the oxidation of $[4 \mathrm{Fe}-4 \mathrm{~S}]$ by $\mathrm{H}_{2} \mathrm{O}_{2}$ leads to ferryl-radical $[4 \mathrm{Fe}-4 \mathrm{~S} / \mathrm{O}]^{2+}$ clusters (Equation (6a)) from which [3Fe-4S $]^{+}$clusters are derived (Equation (6b)) [277]. Nevertheless, $\mathrm{Fe}^{2+}$ and $\mathrm{H}_{2} \mathrm{O}_{2}$ represent harmful byproducts of Fe-S cluster oxidation (Equations (1) and (3)) which may generate ${ }^{\bullet} \mathrm{OH}$ radicals in the Fenton reaction (Equation (7)). Indeed, Fe-S oxidation-based ${ }^{\bullet} \mathrm{OH}$ radical formation represents a potent killing mechanism in bacteria, which is supposed to underlie the $\mathrm{H}_{2} \mathrm{O}_{2}$-based antimicrobial defenses used by higher organisms [257,277]. Moreover, inactivation of mitochondrial aconitase by $\mathrm{O}_{2}{ }^{\bullet-}$ mediated $\mathrm{Fe}-\mathrm{S}$ cluster oxidation causes necrotic cell death of embryonic rat cortical cells [276] which may be connected with the interruption of energy metabolism (mitochondrial aconitase-ACO2 - is a key enzyme of the TCA cycle) and Fenton-reaction-based ${ }^{\bullet} \mathrm{OH}$ formation as stated above. With respect to the abundance of Fe-S cluster containing proteins of the respiratory chain, enhanced ${ }^{\circ} \mathrm{OH}$ formation in fact could be of considerable relevance since it may directly exert protein damage and also stimulate lipid peroxidation (LPO), aldehydic LPO metabolites such as malondialdehyde or HNE leading to mitochondrial malfunction, instability and cellular collapse [208,280-286]. For instance, HNE may form adducts with cysteine residues of the cubane $\mathrm{Fe}-\mathrm{S}$ cluster and the catalytic center of ACO2 which substantially lowers the enzymatic activity [287] and could also interfere with the RNA binding properties.

Moderate cytosolic Fe-S cluster oxidation changing the cluster conformation to the [3Fe-4S] state will abolish IRP-1 c-aconitase activity but this not necessarily is sufficient to induce IRP-1 mRNA 
binding activity [288]. Enhanced pro-oxidant conditions, however, will stimulate cluster decomposition, which promotes IRP-1 RNA binding, an effect which is of particular relevance to iron metabolism in cultured cells exposed to increased, non-physiologic oxygen concentrations [265]. Interestingly, IRP-1 RNA binding is stimulated by extracellular $\mathrm{H}_{2} \mathrm{O}_{2}$ while the endogenous, cytosolic $\mathrm{H}_{2} \mathrm{O}_{2}$ production shows no comparable effect [289,290]. This suggests the involvement of additional, Fe-S cluster independent, mechanisms controlling IRP-1 activity. Indeed, IRP-1 contains a phosphorylation site for protein kinase C [291,292], which allows an integration of IRP-1 activity in cellular stress responses. Moreover, phosphorylation of IRP-1 sensitizes for iron-dependent protein degradation and by this controls IRP-1 abundance per se [293]. Similarly, enhanced oxidative stress and massive iron overload also facilitate IRP-1 degradation, which will enhance iron buffering by altered ferritin synthesis at a limited TfR-based iron uptake [294-296]. Albeit this suggests that ROS triggered IRP-1 degradation acts as "emergency break", limiting the labile iron pool under pro-oxidant conditions [267,275,297], IRP-1 degradation not necessarily changes intracellular iron levels [298]. Thus, under conditions of increased oxidative stress, the labile iron pool may be controlled by more than a single IRP-1-based mechanism.

Hence, IRP-1 apparently regulates iron homeodynamics at rather extreme conditions. While IRP-1 degradation restricts the labile iron pool at elevated ROS concentrations, IRP-1 RNA-binding counteracts iron-depletion and stabilizes the LIP under moderately increased oxidative stress, both mechanisms also controllable by additional cellular stress signals via IRP-1 phosphorylation. However, it should not be ignored that stimulation of IRP-1 RNA-binding by moderate ROS attack may also occur under iron-replete conditions which may promote cellular iron overload. Concerning the ELC/ELIP, this inappropriate response is prone to generate lysosomal stress, which alters the susceptibility for lysosome mediated cell death under pro-oxidant conditions [299,300]. Complicating the issue, inactivation of IRP-1 c-aconitase activity by Fe-S cluster oxidation will also weaken antioxidant defenses since IRP-1 c-aconitase activity contributes to both glutathione (GSH) synthesis and NADPH generation which is necessary for the reduction of oxidized glutathione (GSSG) [301-304]. Thus, a cytotoxic condition can readily emerge from mild oxidative stress if oxidation of IRP-1 Fe-S clusters leads to an inadequate disturbance of iron homeodynamics and antioxidant defenses.

\section{3. $I R P-2$}

Similar to IRP-1, iron regulatory protein 2 (IRP-2) also shows RNA-binding properties, however, lacks Fe-S clusters as well as aconitase activity and is regulated via proteasome-mediated degradation [265,305-309]. Among several target mRNAs, IRP-2 shows a preference to bind to ferritin $\mathrm{H}$ and $\mathrm{L}$ chain mRNA which is stabilized by proteasome inhibitors abrogating ferritin synthesis while iron-rich conditions promote proteasomal decomposition of IRP-2 [310-312]. Hypoxia stabilizes IRP-2 RNA binding too, which is also antagonized by iron [307,313,314]. Importantly, at physiologic oxygen concentrations (3\%) IRP control of cellular iron levels is mainly exerted by IRP-2, IRP-1 showing little mRNA binding activity and marginal iron responsiveness [314,315]. On the contrary, at increased tissue oxygen tensions, IRP-2 abundance declines and IRP-1 adopts the role as main iron regulatory protein [314] as discussed above. IRP-2 RNA binding is upregulated by phosphorylation, which, different from IRP-1, is iron dependent and does not increase IRP degradation [293,316]. However, similar to IRP-1, phosphorylation links IRP-2 activity to intra- and extracellular signaling 
which may serve cell proliferation and differentiation [316]. For instance, it has been shown that IRP-2 couples Jak/Stat5 signaling to TfR expression in erythropoiesis [317]. Also, IRP-2 knock out mice show disturbances of dopamine regulation as well as iron overload and increased ferritin expression in distinct brain areas and it is suggested that iron mismanagement upon loss of IRP-2 control accelerates the aging of dopaminergic neurons [318,319]. As stated above, IRP-2 is considered to be the main regulator of iron metabolism under normal conditions and may compensate for IRP-1 deficiency [320]. However, the responsiveness of IRP-1 and 2 to stress related stimuli, which may involve changes of the phosphorylation state, points at distinct roles of both IRPs in controlling the cellular labile iron pool under stress conditions.

\subsection{NO Signaling and IRP Regulation}

Nitric oxide synthase (NOS) generated nitric oxide $\left(\mathrm{NO}^{\bullet}\right)$ and peroxynitrite $\left(\mathrm{ONOO}^{-}\right)$derived thereof by reaction with superoxide $\left(\mathrm{NO}^{\bullet}\right.$ and $\mathrm{ONOO}^{-}$representing reactive nitrogen species- $\mathrm{RNS}$ ) are able to react with Fe contained in proteins as heme or Fe-S cluster bound iron [321-327]. Of note, $\mathrm{NO}^{\bullet}$ which has a high affinity to iron [328] can mobilize iron from ferritin in a GSH dependent manner $[329,330]$. In addition, $\mathrm{NO}^{\bullet}$ as well as the nitrosonium cation $\left(\mathrm{NO}^{+}\right)$can S-nitrosylate thiol groups of proteins including ferritin and IRPs which confers important regulatory functions in iron metabolism including changes of ferritin and TfR synthesis [328,331-335]. NO may also react with ferrous "labile" iron and thiol containing GSH which generates dinitrosyl-iron complexes [336] leading to S-nitrosothiol formation [337,338]. Of special relevance, nitrosylation of GSH by $\mathrm{NO}^{+}$ produces S-nitrosoglutathione (GSNO) [339-343] a potent antioxidant which exerts cytoprotective properties [341,344-350] albeit a hepatocytotoxic effect of GSNO has also been reported [351].

Several investigations have addressed the interference of NO-signaling with IRP-1 and 2 activity via $\mathrm{NO}^{\bullet} / \mathrm{ONOO}^{-}-\mathrm{Fe}-\mathrm{S}$ cluster interaction and IRP S-nitrosylation-which may reversibly $\left(\mathrm{NO}^{+}\right)$ or irreversibly $\left(\mathrm{ONOO}^{-}\right)$inhibit IRP-1 aconitase activity, stabilize IRP-1 RNA binding $(\mathrm{NO} \bullet)$ or irreversibly modify IRP-1 thus abrogating RNA binding $\left(\mathrm{ONOO}^{-}\right)$and also affect IRP-2 stability [311,325,332,333,352-361]. In particular, the enhanced degradation of IRP-2 mediated by NOS derived $\mathrm{NO}^{\bullet}$ which triggers ferritin synthesis in cells exposed to proinflammatory stimuli points at the importance of NO-signaling in pathophysiological contexts [311,352,357]. However, it has been reported that $\mathrm{NO}^{\bullet}$ can also stabilize IRP-2 probably by LIP interference [359,361,362] while IRP-2 degradation is promoted by $\mathrm{NO}^{+}$mediated nitrosylation [333]. Notably, $\mathrm{NO}^{+}$is able to stimulate ferritin synthesis also in an IRP-2 independent mode [311]. Hence, cellular iron homeodynamics is regulated by nitrogen species based on complex, feedback-regulated mechanisms, the expression of NOS and thus NO levels itself being directly affected by cellular iron levels [363]. Moreover, NO-signaling also allows an intercellular control of iron pools and by this may contribute to cell-cell interaction mediated changes of iron homeodynamics. Albeit is has been shown that macrophages stimulate iron release from target cells [364] it is questionable whether this is mediated by NO, however, evidence exists that NO can limit transferrin/TfR-based iron uptake (discussed in [365]). 


\subsection{Additional Regulatory Roles of IRPS}

Recently, additional functions of IRPs have been identified which are more indirectly related to iron metabolism (reviewed in [366]). In particular, it has been shown that IRP-1 also acts as negative translational regulator of hypoxia-inducible factor $2 \alpha$ (HIF2 $\alpha$ ) [367]. This interference affects several downstream targets of HIF2 $\alpha$ such as erythropoietin (EPO) expression and by this erythropoiesis and hepcidin expression [368-372] as well as transcriptional activation of Fpn and DMT-1 [373-375] in addition to the IRP-1/mRNA-based regulation. Since HIF2 $\alpha$, like HIF1 $\alpha$, also affects tumor progression and tumor stem cell function [376,377], IRP-1 could also play a role in tumorigenesis. Moreover, tumor cell proliferation is enhanced upon overexpression of IRP-2 [378], the oncogene c-myc upregulating IRP-2 but repressing H-ferritin [379]. Thus, the role of IRPs may change in the course of neoplastic transformation serving the tumor growth associated reprogramming of iron metabolism [380] and cellular iron homeodynamics.

\section{Iron Homeodynamics under Stress Conditions-A Distinct Role for Ferritin?}

Taken together, iron compartmentalization together with iron-, redox- and stress dependent gene expression (on the transcriptional and translational level) constitutes the framework of cellular iron homeodynamics. Transcriptional control of iron metabolism related genes defines a distinct $m R N A$ signature [381] which is translated into an iron management-related proteome serving the dynamic fine-adjustment of intracellular iron balance. Stress conditions will modulate the cell type and condition (e.g., iron requirement, state of differentiation, proliferation) specific $m R N A$ signature and even more specifically its translation, which is under IRP control. IRP activity by itself is directly (IRP-1) or indirectly (IRP-2) regulated by the LIP/CLIP, which involves regulatory feedback loops (e.g., MLIP dependent Fe-S cluster synthesis acting directly on IRP-1) as well as additional stress-related signals (e.g., NO-signaling). Hence, IRPs serve as central guardians of cellular iron homeodynamics and stress tolerance as illustrated in Figure 2.

Under normal conditions iron homeodynamics is predominantly determined by mitochondrial iron consumption (MLIP), IRP-2 serving the dynamic housekeeping adjustment of the LIP. Tightly coordinated with this, IRP-1 c-aconitase activity links the LIP to GSH and NADPH abundance and via this to cellular antioxidant capacity. Oxidative stress markedly interferes with this regulatory network depending on the source (ROS, RNS), severity and persistence of the pro-oxidant stressor. Moderate stress conditions promote Fe-S cluster disassembly and stimulate IRP-1 RNA binding which fosters iron overload. When antioxidant defenses are inadequate, this could aggravate the pro-oxidant condition especially with respect to the lysosomal and mitochondrial compartment. On the other hand, severe or chronic states of increased oxidative stress will lead to enhanced IRP degradation (IRP-1 and 2) which promotes iron (LIP) depletion due to elevated ferritin synthesis and reduced TfR-based iron import. Complicated by the concomitant decline of IRP-1 c-aconitase activity, which interrupts refueling of the antioxidant pools, this pro-oxidant condition readily will become incompatible with cell survival. Therefore, oxidative stress, especially when persistent, demands specific adaptations of iron management that support proper LIP control and continued iron supply for metabolic needs. 


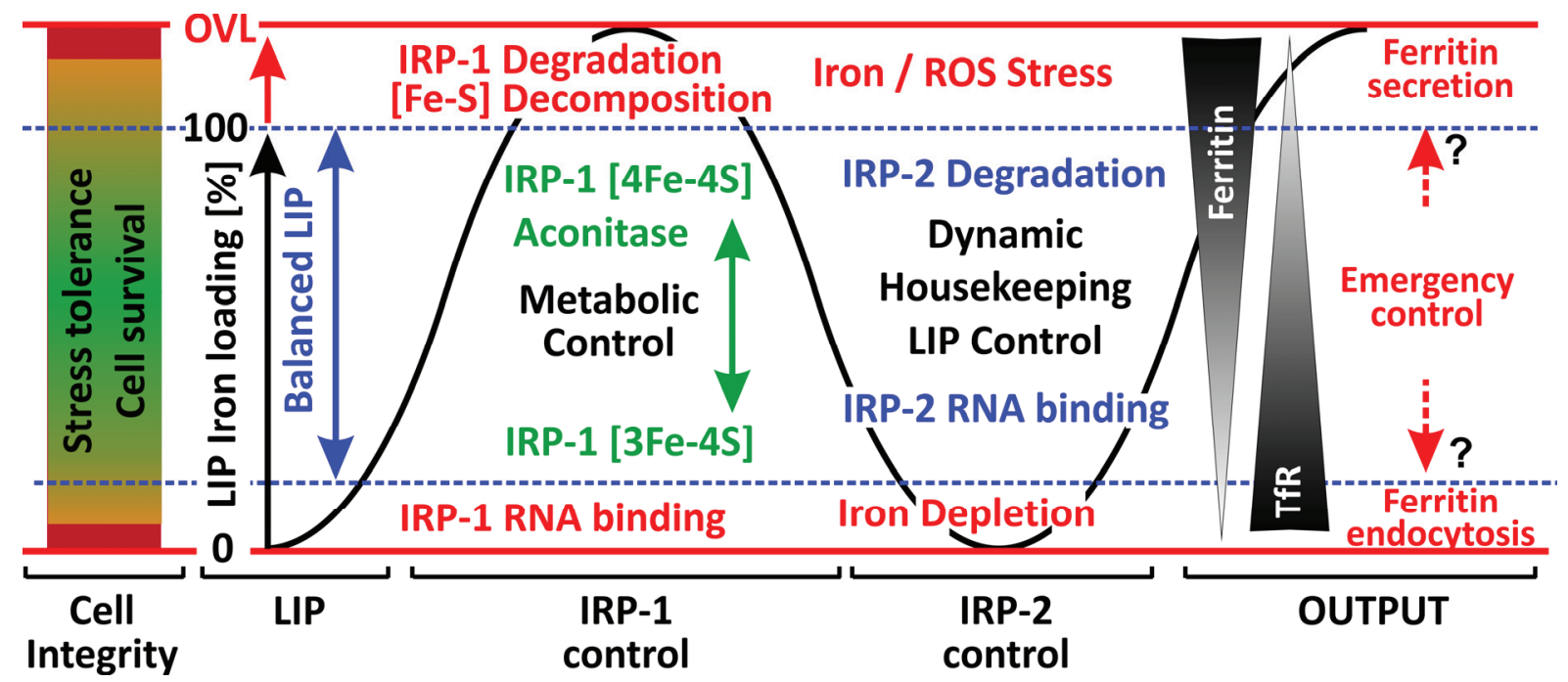

Figure 2. Iron homeodynamics and stress conditions. Cell integrity and stress tolerance demands a balanced LIP between 0 (iron depletion) and 100\% (maximum loading). Under normal conditions (blue range) the LIP is controlled by IRP-2 abundance, IRP-1 preferentially exerting c-aconitase activity depending on Fe-S cluster conformation. Moderately enhanced oxidative stress will promote Fe-S cluster decomposition (see p. 820), while severe pro-oxidant regimens as well as iron overload (OVL) lead to IRP-1 degradation. Iron import via TfR and ferritin-based iron buffering control the LIP in opposite directions depending on the actual iron content and oxidant conditions (Output). It is hypothesized that ferritin exo- and endocytosis serve the "emergency control" of the LIP under conditions of either severe (or chronic) iron overload and oxidative stress or massive iron depletion, respectively.

Moreover, severe ROS attack on iron-loaded ferritin could become a further considerable threat when the "safely stored iron" is liberated rendering the LIP (CLIP) uncontrollable due to an impaired iron buffering capacity. Hypothetically, ferritin/iron-rich cells such as hepatocytes and macrophages as well could face the risk of irreversible ferritin-iron/ROS derived damage by releasing iron loaded ferritin under oxidative stress which would rapidly lower the tenuous iron burden. The increase of serum ferritin associated with hepatic iron overload in ferroportin disease [55] provides support to this assumption. Similarly, in macrophages ferritin release could compensate the heme degradation-based iron charging of the CLIP/ferritin — a notion that fits with the finding that serum ferritin is mainly derived from macrophages [59]—which may increase under oxidative stress [382]. Furthermore, primary hepatocytes release ferritin in vitro in particular at initial culture stages [383,384], the secreted ferritin exerting an iron-dependent cytotoxic effect [95]. It cannot be excluded that this also reflects an attempt of the freshly isolated cells to mitigate the cell isolation derived pro-oxidant condition by emptying their intracellular iron buffer. On the contrary, it should not be neglected that serum ferritin may deliver at least 100 times more iron per molecule than transferrin. Thus, endocytosis of serum ferritin could counteract iron undersupply in cells with enhanced iron needs such as oligodendrocytes and erythroid precursor cells $[24,63]$. 


\section{Conclusions}

In conclusion, cellular iron homeodynamics is based on a well-orchestrated interaction of iron uptake, intracellular transport, iron storage, usage and export, which is embedded in cellular metabolic and surveillance control. Under normal conditions this machinery provides a dynamic response to changing iron requirements and iron supply allowing the constant fueling of intracellular iron metabolism. Under stress conditions, this orchestration changes in order to maintain homeodynamics and protect the cell from severe destabilization. Potentially, this may also involve distinct emergency control mechanism such as the release or uptake of ferritin to and from the extracellular environment, the possible existence of such alternative pathways remaining to be defined.

\section{Abbreviations}

$\begin{array}{ll}\text { CLIP } & \text { cytosolic labile iron pool } \\ \text { DMT1 } & \text { divalent metal transporter } \\ \text { ELC } & \text { endo-/lysosomal compartment } \\ \text { ELIP } & \text { endo-/lysosomal labile iron pool } \\ \text { Fpn } & \text { ferroportin } \\ \text { Ftx } & \text { frataxin } \\ \text { HNE } & \text { 4-hydroxy-nonenal } \\ \text { FRDA } & \text { Friedreich's ataxia } \\ \text { IRE } & \text { iron regulatory elements } \\ \text { IRP } & \text { iron regulatory protein } \\ \text { ISCU } & \text { iron-sulfur cluster forming unit } \\ \text { LIP } & \text { labile iron pool } \\ \text { LMP } & \text { lysosomal membrane permeability } \\ \text { MLIP } & \text { mitochondrial labile iron pool } \\ \text { mtFER } & \text { mitochondrial ferritin } \\ \text { NTBI } & \text { non-transferrin bound iron } \\ \text { RME } & \text { receptor mediated endocytosis } \\ \text { RNS } & \text { reactive nitrogen species } \\ \text { ROS } & \text { reactive oxygen species } \\ \text { TBI } & \text { transferrin-bound iron } \\ \text { TfR } & \text { transferrin receptor } \\ \text { TRPML1 } & \text { type IV mucolipidosis-associated protein } \\ & \end{array}$

\section{Conflicts of Interest}

The authors declare no conflict of interest. 


\section{References}

1. Shayeghi, M.; Latunde-Dada, G.O.; Oakhill, J.S.; Laftah, A.H.; Takeuchi, K.; Halliday, N.; Khan, Y.; Warley, A.; McCann, F.E.; Hider, R.C.; et al. Identification of an intestinal heme transporter. Cell 2005, 122, 789-801.

2. Garrick, M.D.; Dolan, K.G.; Horbinski, C.; Ghio, A.J.; Higgins, D.; Porubcin, M.; Moore, E.G.; Hainsworth, L.N.; Umbreit, J.N.; Conrad, M.E.; et al. DMT1: A mammalian transporter for multiple metals. Biometals 2003, 16, 41-54.

3. Andrews, N.C. The iron transporter DMT1. Int. J. Biochem. Cell Biol. 1999, 31, 991-994.

4. Garrick, M.D.; Garrick, L.M. Cellular iron transport. Biochim. Biophys. Acta Gen. Subj. 2009, 1790, 309-325.

5. Conrad, M.E.; Umbreit, J.N.; Moore, E.G.; Hainsworth, L.N.; Porubcin, M.; Simovich, M.J.; Nakada, M.T.; Dolan, K.; Garrick, M.D. Separate pathways for cellular uptake of ferric and ferrous iron. Am. J. Physiol. Gastrointest. Liver Physiol. 2000, 279, G767-G774.

6. Conrad, M.E.; Umbreit, J.N. Pathways of iron absorption. Blood Cells Mol. Dis. 2002, 29, 336-355.

7. Fuqua, B.K.; Vulpe, C.D.; Anderson, G.J. Intestinal iron absorption. J. Trace Elem. Med. Biol. 2012, 26, 115-119.

8. Liuzzi, J.P.; Aydemir, F.; Nam, H.; Knutson, M.D.; Cousins, R.J. Zip14 (Slc39a14) mediates non-transferrin-bound iron uptake into cells. Proc. Natl. Acad. Sci. USA 2006, 103, 13612-13617.

9. Pinilla-Tenas, J.J.; Sparkman, B.K.; Shawki, A.; Illing, A.C.; Mitchell, C.J.; Zhao, N.; Liuzzi, J.P.; Cousins, R.J.; Knutson, M.D.; Mackenzie, B. Zip14 is a complex broad-scope metal-ion transporter whose functional properties support roles in the cellular uptake of zinc and nontransferrin-bound iron. Am. J. Physiol. Cell Physiol. 2011, 301, C862-C871.

10. Graham, R.M.; Morgan, E.H.; Baker, E. Characterisation of citrate and iron citrate uptake by cultured rat hepatocytes. J. Hepatol. 1998, 29, 603-613.

11. Baker, E.; Baker, S.M.; Morgan, E.H. Characterisation of non-transferrin-bound iron (ferric citrate) uptake by rat hepatocytes in culture. Biochim. Biophys. Acta Gen. Subj. 1998, 1380, 21-30.

12. Graham, R.M.; Morgan, E.H.; Baker, E. Ferric citrate uptake by cultured rat hepatocytes is inhibited in the presence of transferrin. Eur. J. Biochem. 1998, 253, 139-145.

13. Cighetti, G.; Duca, L.; Bortone, L.; Sala, S.; Nava, I.; Fiorelli, G.; Cappellini, M.D. Oxidative status and malondialdehyde in $\beta$-thalassaemia patients. Eur. J. Clin. Investig. 2002, 32, 55-60.

14. Porter, J.B.; Garbowski, M. The Pathophysiology of Transfusional Iron Overload. Hematol. Oncol. Clin. N. Am. 2014, 28, 683-701.

15. De Luca, C.; Filosa, A.; Grandinetti, M.; Maggio, F.; Lamba, M.; Passi, S. Blood antioxidant status and urinary levels of catecholamine metabolites in beta-thalassemia. Free Radic. Res. 1999, 30, 453-462.

16. Esposito, B.P.; Breuer, W.; Sirankapracha, P.; Pootrakul, P.; Hershko, C.; Cabantchik, Z.I. Labile plasma iron in iron overload: redox activity and susceptibility to chelation. Blood 2003, 102, 2670-2677.

17. Hershko, C.; Link, G.; Cabantchik, I. Pathophysiology of iron overload. Ann. NY Acad. Sci. 1998, 850, 191-201. 
18. Gutteridge, J.M.; Rowley, D.A.; Griffiths, E.; Halliwell, B. Low-molecular-weight iron complexes and oxygen radical reactions in idiopathic haemochromatosis. Clin. Sci. 1985, 68, 463-467.

19. Sibille, J.C.; Kondo, H.; Aisen, P. Interactions between isolated hepatocytes and Kupffer cells in iron metabolism: A possible role for ferritin as an iron carrier protein. Hepatology 1988, 8, 296-301.

20. Sibille, J.C.; Kondo, H.; Aisen, P. Uptake of ferritin and iron bound to ferritin by rat hepatocytes: Modulation by apotransferrin, iron chelators and chloroquine. Biochim. Biophys. Acta 1989, 1010, 204-209.

21. Wang, W.; Knovich, M.A.; Coffman, L.G.; Torti, F.M.; Torti, S.V. Serum ferritin: Past, present and future. Biochim. Biophys. Acta 2010, 1800, 760-769.

22. Sibille, J.C.; Ciriolo, M.; Kondo, H.; Crichton, R.R.; Aisen, P. Subcellular localization of ferritin and iron taken up by rat hepatocytes. Biochem. J. 1989, 262, 685-688.

23. Kalgaonkar, S.; Lonnerdal, B. Receptor-mediated uptake of ferritin-bound iron by human intestinal Caco-2 cells. J. Nutr. Biochem. 2009, 20, 304-311.

24. Gelvan, D.; Fibach, E.; Meyron-Holtz, E.G.; Konijn, A.M. Ferritin uptake by human erythroid precursors is a regulated iron uptake pathway. Blood 1996, 88, 3200-3207.

25. Meyron-Holtz, E.G.; Fibach, E.; Gelvan, D.; Konijn, A.M. Binding and uptake of exogenous isoferritins by cultured human erythroid precursor cells. Br. J. Haematol. 1994, 86, 635-641.

26. Hulet, S.W.; Hess, E.J.; Debinski, W.; Arosio, P.; Bruce, K.; Powers, S.; Connor, J.R. Characterization and distribution of ferritin binding sites in the adult mouse brain. J. Neurochem. 1999, 72, 868-874.

27. Liao, Q.K.; Kong, P.A.; Gao, J.; Li, F.Y.; Qian, Z.M. Expression of ferritin receptor in placental microvilli membrane in pregnant women with different iron status at mid-term gestation. Eur. $J$. Clin. Nutr. 2001, 55, 651-656.

28. Mack, U.; Storey, E.L.; Powell, L.W.; Halliday, J.W. Characterization of the binding of ferritin to the rat liver ferritin receptor. Biochim. Biophys. Acta 1985, 843, 164-170.

29. Takami, M.; Mizumoto, K.; Kasuya, I.; Kino, K.; Sussman, H.H.; Tsunoo, H. Human placental ferritin receptor. Biochim. Biophys. Acta Gen. Subj. 1986, 884, 31-38.

30. Hulet, S.W.; Heyliger, S.O.; Powers, S.; Connor, J.R. Oligodendrocyte progenitor cells internalize ferritin via clathrin-dependent receptor mediated endocytosis. J. Neurosci. Res. 2000, 61, 52-60.

31. Chen, T.T.; Li, L.; Chung, D.-H.; Allen, C.D.C.; Torti, S.V.; Torti, F.M.; Cyster, J.G.; Chen, C.-Y.; Brodsky, F.M.; Niemi, E.C.; et al. TIM-2 is expressed on B cells and in liver and kidney and is a receptor for H-ferritin endocytosis. J. Exp. Med. 2005, 202, 955-965.

32. Todorich, B.; Zhang, X.; Slagle-Webb, B.; Seaman, W.E.; Connor, J.R. Tim-2 is the receptor for H-ferritin on oligodendrocytes. J. Neurochem. 2008, 107, 1495-1505.

33. Li, J.Y.; Paragas, N.; Ned, R.M.; Qiu, A.; Viltard, M.; Leete, T.; Drexler, I.R.; Chen, X.; Sanna-Cherchi, S.; Mohammed, F.; et al. Scara5 is a ferritin receptor mediating non-transferrin iron delivery. Dev. Cell 2009, 16, 35-46.

34. Li, L.; Fang, C.J.; Ryan, J.C.; Niemi, E.C.; Lebron, J.A.; Björkman, P.J.; Arase, H.; Torti, F.M.; Torti, S.V.; Nakamura, M.C.; et al. Binding and uptake of H-ferritin are mediated by human transferrin receptor-1. Proc. Natl. Acad. Sci. USA 2010, 107, 3505-3510. 
35. Thomsen, J.H.; Etzerodt, A.; Svendsen, P.; Moestrup, S.K. The haptoglobin-CD163-heme oxygenase-1 pathway for hemoglobin scavenging. Oxid. Med. Cell. Longev. 2013, doi:10.1155/2013/523652.

36. Nairz, M.; Schroll, A.; Demetz, E.; Tancevski, I.; Theurl, I.; Weiss, G. "Ride on the ferrous wheel"-The cycle of iron in macrophages in health and disease. Immunobiology 2014, 220, 280-294.

37. Abboud, S.; Haile, D.J. A Novel mammalian iron-regulated protein involved in intracellular iron metabolism. J. Biol. Chem. 2000, 275, 19906-19912.

38. McKie, A.; Barlow, D. The SLC40 basolateral iron transporter family (IREG1/ferroportin/MTP1). Pflüg. Arch. 2004, 447, 801-806.

39. Musci, G.; Polticelli, F.; Bonaccorsi di Patti, M.C. Ceruloplasmin-ferroportin system of iron traffic in vertebrates. World J. Biol. Chem. 2014, 5, 204-215.

40. Donovan, A.; Lima, C.A.; Pinkus, J.L.; Pinkus, G.S.; Zon, L.I.; Robine, S.; Andrews, N.C. The iron exporter ferroportin/Slc40a1 is essential for iron homeostasis. Cell Metab. 2005, 1, 191-200.

41. Donovan, A.; Brownlie, A.; Zhou, Y.; Shepard, J.; Pratt, S.J.; Moynihan, J.; Paw, B.H.; Drejer, A.; Barut, B.; Zapata, A.; et al. Positional cloning of zebrafish ferroportin1 identifies a conserved vertebrate iron exporter. Nature 2000, 403, 776-781.

42. Nemeth, E.; Tuttle, M.S.; Powelson, J.; Vaughn, M.B.; Donovan, A.; Ward, D.M.; Ganz, T.; Kaplan, J. Hepcidin regulates cellular iron efflux by binding to ferroportin and inducing its internalization. Science 2004, 306, 2090-2093.

43. Ganz, T. Hepcidin and iron regulation, 10 years later. Blood 2011, 117, 4425-4433.

44. Folgueras, A.R.; de Lara, F.M.; Pendás, A.M.; Garabaya, C.; Rodríguez, F.; Astudillo, A.; Bernal, T.; Cabanillas, R.; López-Otín, C.; Velasco, G. Membrane-bound serine protease matriptase-2 (Tmprss6) is an essential regulator of iron homeostasis. Blood 2008, 112, 2539-2545.

45. Du, X.; She, E.; Gelbart, T.; Truksa, J.; Lee, P.; Xia, Y.; Khovananth, K.; Mudd, S.; Mann, N.; Moresco, E.M.Y.; et al. The serine protease TMPRSS6 is required to sense iron deficiency. Science 2008, 320, 1088-1092.

46. Harris, Z.L.; Durley, A.P.; Man, T.K.; Gitlin, J.D. Targeted gene disruption reveals an essential role for ceruloplasmin in cellular iron efflux. Proc. Natl. Acad. Sci. USA 1999, 96, 10812-10817.

47. Vulpe, C.D.; Kuo, Y.-M.; Murphy, T.L.; Cowley, L.; Askwith, C.; Libina, N.; Gitschier, J.; Anderson, G.J. Hephaestin, a ceruloplasmin homologue implicated in intestinal iron transport, is defective in the sla mouse. Nat. Genet. 1999, 21, 195-199.

48. Vashchenko, G.; MacGillivray, R. Multi-copper oxidases and human iron metabolism. Nutrients 2013, 5, 2289-2313.

49. Nicolas, G.; Bennoun, M.; Devaux, I.; Beaumont, C.; Grandchamp, B.; Kahn, A.; Vaulont, S. Lack of hepcidin gene expression and severe tissue iron overload in upstream stimulatory factor 2 (USF2) knockout mice. Proc. Natl. Acad. Sci. USA 2001, 98, 8780-8785.

50. Nicolas, G.; xEb; Chauvet, C.; Viatte, L.; Danan, J.L.; Bigard, X.; Devaux, I.; Beaumont, C.; Kahn, A.; Vaulont, S. The gene encoding the iron regulatory peptide hepcidin is regulated by anemia, hypoxia, and inflammation. J. Clin. Invest. 2002, 110, 1037-1044. 
51. Chaston, T.B.; Matak, P.; Pourvali, K.; Srai, S.K.; McKie, A.T.; Sharp, P.A. Hypoxia inhibits hepcidin expression in HuH7 hepatoma cells via decreased SMAD4 signaling. Am. J. Physiol. Cell Physiol. 2011, 300, C888-C895.

52. Peyssonnaux, C.; Zinkernagel, A.S.; Schuepbach, R.A.; Rankin, E.; Vaulont, S.; Haase, V.H.; Nizet, V.; Johnson, R.S. Regulation of iron homeostasis by the hypoxia-inducible transcription factors (HIFs). J. Clin. Invest. 2007, 117, 1926-1932.

53. Hintze, K.J.; McClung, J.P. Hepcidin: A critical regulator of iron metabolism during hypoxia. Adv. Hematol. 2011, doi:10.1155/2011/510304.

54. Song, N.; Wang, J.; Jiang, H.; Xie, J. Ferroportin1 and hephaestin overexpression attenuate iron-induced oxidative stress in MES23.5 dopaminergic cells. J. Cell. Biochem. 2010, 110, 1063-1072.

55. Pietrangelo, A. The ferroportin disease. Blood Cells Mol. Dis. 2004, 32, 131-138.

56. Nemeth, E.; Valore, E.V.; Territo, M.; Schiller, G.; Lichtenstein, A.; Ganz, T. Hepcidin, a putative mediator of anemia of inflammation, is a type II acute-phase protein. Blood 2003, 101, 2461-2463.

57. Ghosh, S.; Hevi, S.; Chuck, S.L. Regulated secretion of glycosylated human ferritin from hepatocytes. Blood 2004, 103, 2369-2376.

58. Tran, T.N.; Eubanks, S.K.; Schaffer, K.J.; Zhou, C.Y.; Linder, M.C. Secretion of ferritin by rat hepatoma cells and its regulation by inflammatory cytokines and iron. Blood 1997, 90, 4979-4986.

59. Cohen, L.A.; Gutierrez, L.; Weiss, A.; Leichtmann-Bardoogo, Y.; Zhang, D.-L.; Crooks, D.R.; Sougrat, R.; Morgenstern, A.; Galy, B.; Hentze, M.W.; et al. Serum ferritin is derived primarily from macrophages through a nonclassical secretory pathway. Blood 2010, 116, 1574-1584.

60. Van Deurs, B.; Von Bulow, F.; Moller, M. Vesicular transport of cationized ferritin by the epithelium of the rat choroid plexus. J. Cell Biol. 1981, 89, 131-139.

61. Fisher, J.; Devraj, K.; Ingram, J.; Slagle-Webb, B.; Madhankumar, A.B.; Liu, X.; Klinger, M.; Simpson, I.A.; Connor, J.R., Ferritin: A novel mechanism for delivery of iron to the brain and other organs. Am. J. Physiol. Cell Physiol. 2007, 293, C641-C649.

62. Meyron-Holtz, E.; Moshe-Belizowski, S.; Cohen, L. A possible role for secreted ferritin in tissue iron distribution. J. Neural Transm. 2011, 118, 337-347.

63. Todorich, B.; Zhang, X.; Connor, J.R. H-ferritin is the major source of iron for oligodendrocytes. Glia 2011, 59, 927-935.

64. Knovich, M.A.; Storey, J.A.; Coffman, L.G.; Torti, S.V.; Torti, F.M. Ferritin for the clinician. Blood Rev. 2009, 23, 95-104.

65. Casgrain, A.; Collings, R.; Harvey, L.J.; Hooper, L.; Fairweather-Tait, S.J. Effect of iron intake on iron status: A systematic review and meta-analysis of randomized controlled trials. Am. J. Clin. Nutr. 2012, 96, 768-780.

66. Yip, R. Changes in iron metabolism with age. In Iron Metabolism in Health and Disease; Brock, J.H., Halliday, J.W., Pippard, M.J., Powell, L.W.E., Eds.; WB Saunders: London, UK, 1994; pp. 428-448.

67. Finch, C.A.; Bellotti, V.; Stray, S.; Lipschitz, D.A.; Cook, J.D.; Pippard, M.J.; Huebers, H.A. Plasma ferritin determination as a diagnostic tool. West. J. Med. 1986, 145, 657-663.

68. Ferraro, S.; Mozzi, R.; Panteghini, M. Revaluating serum ferritin as a marker of body iron stores in the traceability era. Clin. Chem. Lab. Med. 2012, 50, 1911-1916. 
69. Karlsson, T.; Sjöö, F.; Kedinge-Cyrus, B.; Bäckström, B. Plasma soluble transferrin receptor assay when screening for iron-deficiency in an unselected population of elderly anaemic patients. J. Intern. Med. 2010, 267, 331-334.

70. Alkhateeb, A.A.; Connor, J.R. The significance of ferritin in cancer: Anti-oxidation, inflammation and tumorigenesis. Biochim. Biophys. Acta Rev. Cancer 2013, 1836, 245-254.

71. Fan, K.; Gao, L.; Yan, X. Human ferritin for tumor detection and therapy. Wiley Interdiscip. Rev. Nanomed. Nanobiotechnol. 2013, 5, 287-298.

72. Fairweather-Tait, S.J.; Wawer, A.A.; Gillings, R.; Jennings, A.; Myint, P.K. Iron status in the elderly. Mech. Ageing Dev. 2014, 136-137, 22-28.

73. Dong, X.-P.; Cheng, X.; Mills, E.; Delling, M.; Wang, F.; Kurz, T.; Xu, H. The type IV mucolipidosis-associated protein TRPML1 is an endolysosomal iron release channel. Nature 2008, 455, 992-996.

74. Jenkitkasemwong, S.; Wang, C.-Y.; Mackenzie, B.; Knutson, M. Physiologic implications of metal-ion transport by ZIP14 and ZIP8. Biometals 2012, 25, 643-655.

75. Zhao, N.; Gao, J.; Enns, C.A.; Knutson, M.D. ZRT/IRT-like protein 14 (ZIP14) promotes the cellular assimilation of iron from transferrin. J. Biol. Chem. 2010, 285, 32141-32150.

76. Zeevi, D.A.; Frumkin, A.; Bach, G. TRPML and lysosomal function. Biochim. Biophys. Acta 2007, 1772, 851-858.

77. Berberat, P.O.; Katori, M.; Kaczmarek, E.; Anselmo, D.; Lassman, C.; Ke, B.; Shen, X.; Busuttil, R.W.; Yamashita, K.; Csizmadia, E.; et al. Heavy chain ferritin acts as antiapoptotic gene that protects livers from ischemia reperfusion injury. FASEB J. 2003, 17, 1724-1726.

78. Arosio, P.; Ingrassia, R.; Cavadini, P. Ferritins: A family of molecules for iron storage, antioxidation and more. Biochim. Biophys. Acta Gen. Subj. 2009, 1790, 589-599.

79. Breuer, W.; Shvartsman, M.; Cabantchik, Z.I. Intracellular labile iron. Int. J. Biochem. Cell Biol. 2008, 40, 350-354.

80. Kruszewski, M. Labile iron pool: The main determinant of cellular response to oxidative stress. Mutat. Res. Fundam. Mol. Mech. Mutagen. 2003, 531, 81-92.

81. Petrat, F.; de Groot, H.; Sustmann, R.; Rauen, U. The chelatable iron pool in living cells: A methodically defined quantity. Biol. Chem. 2002, 383, 489-502.

82. Rauen, U.; Springer, A.; Weisheit, D.; Petrat, F.; Korth, H.-G.; de Groot, H.; Sustmann, R. Assessment of chelatable mitochondrial iron by using mitochondrion-selective fluorescent iron indicators with different iron-binding affinities. ChemBioChem 2007, 8, 341-352.

83. Cabantchik, Z.I.; Kakhlon, O.; Epsztejn, S.; Zanninelli, G.; Breuer, W. Intracellular and extracellular labile iron pools. Adv. Exp. Med. Biol. 2002, 509, 55-75.

84. Petrat, F.; de Groot, H.; Rauen, U. Subcellular distribution of chelatable iron: A laser scanning microscopic study in isolated hepatocytes and liver endothelial cells. Biochem. J. 2001, 356, 61-69.

85. Ulvik, R.J. Relevance of ferritin-binding sites on isolated mitochondria to the mobilization of iron from ferritin. Biochim. Biophys. Acta 1982, 715, 42-51.

86. Sohn, Y.S.; Breuer, W.; Munnich, A.; Cabantchik, Z.I. Redistribution of accumulated cell iron: A modality of chelation with therapeutic implications. Blood 2008, 111, 1690-1699. 
87. Richardson, D.R.; Lane, D.J.R.; Becker, E.M.; Huang, M.L.-H.; Whitnall, M.; Rahmanto, Y.S.; Sheftel, A.D.; Ponka, P. Mitochondrial iron trafficking and the integration of iron metabolism between the mitochondrion and cytosol. Proc. Natl. Acad. Sci. USA 2010, 107, 10775-10782.

88. Richardson, D.; Ponka, P.; Vyoral, D. Distribution of iron in reticulocytes after inhibition of heme synthesis with succinylacetone: Examination of the intermediates involved in iron metabolism. Blood 1996, 87, 3477-3488.

89. Ponka, P. Tissue-Specific regulation of iron metabolism and heme synthesis: Distinct control mechanisms in erythroid cells. Blood 1997, 89, 1-25.

90. Shvartsman, M.; Kikkeri, R.; Shanzer, A.; Cabantchik, Z.I. Non-transferrin-bound iron reaches mitochondria by a chelator-inaccessible mechanism: Biological and clinical implications. Am. J. Physiol. Cell Physiol. 2007, 293, C1383-C1394.

91. Zhang, A.-S.; Sheftel, A.D.; Ponka, P. Intracellular kinetics of iron in reticulocytes: Evidence for endosome involvement in iron targeting to mitochondria. Blood 2005, 105, 368-375.

92. Kurz, T.; Gustafsson, B.; Brunk, U.T. Intralysosomal iron chelation protects against oxidative stress-induced cellular damage. FEBS J. 2006, 273, 3106-3117.

93. Garner, B.; Roberg, K.; Brunk, U.T. Endogenous ferritin protects cells with iron-laden lysosomes against oxidative stress. Free Radic. Res. 1998, 29, 103-114.

94. Kurz, T.; Gustafsson, B.; Brunk, U.T. Cell sensitivity to oxidative stress is influenced by ferritin autophagy. Free Radic. Biol. Med. 2011, 50, 1647-1658.

95. Bresgen, N.; Jaksch, H.; Lacher, H.; Ohlenschläger, I.; Uchida, K.; Eckl, P.M. Iron mediated oxidative stress plays an essential role in ferritin induced cell death. Free Radic. Biol. Med. 2010, 48, 1347-1357.

96. Krenn, M.A.; Schürz, M.; Teufl, B.; Uchida, K.; Eckl, P.M.; Bresgen, N. Ferritin stimulated lipid peroxidation, lysosomal leak and macroautophagy promote lysosomal "metastability" in primary hepatocytes determining in vitro cell survival. Free Radic. Biol. Med. 2015, 80, 45-58.

97. Umbreit, J.N.; Conrad, M.E.; Moore, E.G.; Desai, M.P.; Turrens, J. Paraferritin: A protein complex with ferrireductase activity is associated with iron absorption in rats. Biochemistry 1996, 35, 6460-6469.

98. Umbreit, J.N.; Conrad, M.E.; Hainsworth, L.N.; Simovich, M. The ferrireductase paraferritin contains divalent metal transporter as well as mobilferrin. Am. J. Physiol. Gastrointest. Liver Physiol. 2002, 282, G534-G539.

99. Ohgami, R.S.; Campagna, D.R.; Greer, E.L.; Antiochos, B.; McDonald, A.; Chen, J.; Sharp, J.J.; Fujiwara, Y.; Barker, J.E.; Fleming, M.D. Identification of a ferrireductase required for efficient transferrin-dependent iron uptake in erythroid cells. Nat. Genet. 2005, 37, 1264-1269.

100. Ohgami, R.S.; Campagna, D.R.; McDonald, A.; Fleming, M.D. The Steap proteins are metalloreductases. Blood 2006, 108, 1388-1394.

101. Zhang, F.; Tao, Y.; Zhang, Z.; Guo, X.; An, P.; Shen, Y.; Wu, Q.; Yu, Y.; Wang, F. Metalloreductase Steap3 coordinates the regulation of iron homeostasis and inflammatory responses. Haematologica 2012, 97, 1826-1835.

102. Jalanko, A.; Braulke, T. Neuronal ceroid lipofuscinoses. Biochim. Biophys. Acta Mol. Cell Res. 2009, 1793, 697-709.

103. Terman, A.; Brunk, U.T. Lipofuscin. Int. J. Biochem. Cell Biol. 2004, 36, 1400-1404. 
104. Bassi, M.T.; Manzoni, M.; Monti, E.; Pizzo, M.T.; Ballabio, A.; Borsani, G. Cloning of the gene encoding a novel integral membrane protein, mucolipidin-and identification of the two major founder mutations causing mucolipidosis type IV. Am. J. Hum. Genet. 2000, 67, 1110-1120.

105. Sun, M.; Goldin, E.; Stahl, S.; Falardeau, J.L.; Kennedy, J.C.; Acierno, J.S., Jr.; Bove, C.; Kaneski, C.R.; Nagle, J.; Bromley, M.C.; et al. Mucolipidosis type IV is caused by mutations in a gene encoding a novel transient receptor potential channel. Hum. Mol. Genet. 2000, 9, 2471-2478.

106. Watanabe, K.; Yamashita, Y.; Ohgawara, H.; Sekiguchi, M.; Satake, N.; Orino, K.; Yamamoto, S. Iron content of rat serum ferritin. J. Vet. Med. Sci. 2001, 63, 587-589.

107. Worwood, M.; Dawkins, S.; Wagstaff, M.; Jacobs, A. The purification and properties of ferritin from human serum. Biochem. J. 1976, 157, 97-103.

108. Adams, P.C.; Chau, L.A. Uptake of ferritin by isolated rat hepatocytes. Effect of metabolic inhibitors and iron. Clin. Investig. Med. 1993, 16, 15-21.

109. Maejima, I.; Takahashi, A.; Omori, H.; Kimura, T.; Takabatake, Y.; Saitoh, T.; Yamamoto, A.; Hamasaki, M.; Noda, T.; Isaka, Y.; et al. Autophagy sequesters damaged lysosomes to control lysosomal biogenesis and kidney injury. EMBO J. 2013, 32, 2336-2347.

110. Ezaki, J.; Kominami, E.; Ueno, T. Peroxisome degradation in mammals. IUBMB Life 2011, 63, 1001-1008.

111. Ding, W.X.; Yin, X.M. Mitophagy: Mechanisms, pathophysiological roles, and analysis. Biol. Chem. 2012, 393, 547-564.

112. Tolkovsky, A.M. Mitophagy. Biochim. Biophys. Acta Mol. Cell Res. 2009, 1793, 1508-1515.

113. Persson, H.L.; Kurz, T.; Eaton, J.W.; Brunk, U.T. Radiation-induced cell death: Importance of lysosomal destabilization. Biochem. J. 2005, 389, 877-884.

114. Bergamini, E. Autophagy: A cell repair mechanism that retards ageing and age-associated diseases and can be intensified pharmacologically. Mol. Asp. Med. 2006, 27, 403-410.

115. Zhang, Y.; Mikhael, M.; Xu, D.; Li, Y.; Soe-Lin, S.; Ning, B.; Li, W.; Nie, G.; Zhao, Y.; Ponka, P. Lysosomal proteolysis is the primary degradation pathway for cytosolic ferritin and cytosolic ferritin degradation is necessary for iron exit. Antioxid. Redox Signal. 2010, 13, 999-1009.

116. Kurz, T.; Brunk, U.T. Autophagy of HSP70 and chelation of lysosomal iron in a non-redox-active form. Autophagy 2009, 5, 93-95.

117. Yu, Z.; Persson, H.L.; Eaton, J.W.; Brunk, U.T. Intralysosomal iron: A major determinant of oxidant-induced cell death. Free Radic. Biol. Med. 2003, 34, 1243-1252.

118. Persson, H.L.; Nilsson, K.J.; Brunk, U.T. Novel cellular defenses against iron and oxidation: Ferritin and autophagocytosis preserve lysosomal stability in airway epithelium. Redox Rep. 2001, 6, 57-63.

119. Antunes, F.; Cadenas, E. Cellular titration of apoptosis with steady state concentrations of $\mathrm{H}_{2} \mathrm{O}_{2}$ : Submicromolar levels of $\mathrm{H}_{2} \mathrm{O}_{2}$ induce apoptosis through Fenton chemistry independent of the cellular thiol state. Free Radic. Biol. Med. 2001, 30, 1008-1018.

120. Antunes, F.; Cadenas, E.; Brunk, U.T. Apoptosis induced by exposure to a low steady-state concentration of $\mathrm{H}_{2} \mathrm{O}_{2}$ is a consequence of lysosomal rupture. Biochem. J. 2001, 356, 549-555.

121. Kroemer, G.; Jaattela, M. Lysosomes and autophagy in cell death control. Nat. Rev. Cancer 2005, 5, 886-897. 
122. Nilsson, E.; Ghassemifar, R.; Brunk, U.T. Lysosomal heterogeneity between and within cells with respect to resistance against oxidative stress. Histochem. J. 1997, 29, 857-865.

123. Zdolsek, J.M.; Svensson, I. Effect of reactive oxygen species on lysosomal membrane integrity. A study on a lysosomal fraction. Virchows Arch. B 1993, 64, 401-406.

124. Persson, H.L.; Yu, Z.; Tirosh, O.; Eaton, J.W.; Brunk, U.T. Prevention of oxidant-induced cell death by lysosomotropic iron chelators. Free Radic. Biol. Med. 2003, 34, 1295-1305.

125. Yu, Z.; Eaton, J.W.; Persson, H.L. The radioprotective agent, amifostine, suppresses the reactivity of intralysosomal iron. Redox Rep. 2003, 8, 347-355.

126. Ollinger, K.; Brunk, U.T. Cellular injury induced by oxidative stress is mediated through lysosomal damage. Free Radic. Biol. Med. 1995, 19, 565-574.

127. Maiuri, M.C.; Zalckvar, E.; Kimchi, A.; Kroemer, G. Self-eating and self-killing: Crosstalk between autophagy and apoptosis. Nat. Rev. Mol. Cell Biol. 2007, 8, 741-752.

128. Brunk, U.T.; Neuzil, J.; Eaton, J.W., Lysosomal involvement in apoptosis. Redox Rep. 2001, 6, 91-97.

129. Baird, S.K.; Kurz, T.; Brunk, U.T. Metallothionein protects against oxidative stress-induced lysosomal destabilization. Biochem. J. 2006, 394, 275-283.

130. Ghosh, M.; Carlsson, F.; Laskar, A.; Yuan, X.M.; Li, W. Lysosomal membrane permeabilization causes oxidative stress and ferritin induction in macrophages. FEBS Lett. 2011, 585, 623-629.

131. Arosio, P.; Yokota, M.; Drysdale, J.W. Characterization of serum ferritin in iron overload: Possible identity to natural apoferritin. Br. J. Haematol. 1977, 36, 199-207.

132. Harrison, P.M.; Arosio, P. The ferritins: Molecular properties, iron storage function and cellular regulation. Biochim. Biophys. Acta 1996, 1275, 161-203.

133. Arosio, P.; Adelman, T.G.; Drysdale, J.W. On ferritin heterogeneity. Further evidence for heteropolymers. J. Biol. Chem. 1978, 253, 4451-4458.

134. Bomford, A.; Berger, M.; Lis, Y.; Williams, R. The iron content of human liver and spleen isoferritins correlates with their isoelectric point and subunit composition. Biochem. Biophys. Res. Commun. 1978, 83, 334-341.

135. Shi, H.; Bencze, K.Z.; Stemmler, T.L.; Philpott, C.C. A cytosolic iron chaperone that delivers iron to ferritin. Science 2008, 320, 1207-1210.

136. Zhao, G.; Arosio, P.; Chasteen, N.D. Iron(II) and hydrogen peroxide detoxification by human H-chain ferritin. An EPR spin-trapping study. Biochemistry 2006, 45, 3429-3436.

137. Levi, S.; Yewdall, S.J.; Harrison, P.M.; Santambrogio, P.; Cozzi, A.; Rovida, E.; Albertini, A.; Arosio, P. Evidence of H- and L-chains have co-operative roles in the iron-uptake mechanism of human ferritin. Biochem. J. 1992, 288, 591-596.

138. Papaefthymiou, G.C. The Mossbauer and magnetic properties of ferritin cores. Biochim. Biophys. Acta 2010, 1800, 886-897.

139. Linder, M. Mobilization of stored iron in mammals: A Review. Nutrients 2013, 5, 4022-4050.

140. Watt, R.K.; Hilton, R.J.; Graff, D.M. Oxido-reduction is not the only mechanism allowing ions to traverse the ferritin protein shell. Biochim. Biophys. Acta 2010, 1800, 745-759.

141. Cassanelli, S.; Moulis, J. Sulfide is an efficient iron releasing agent for mammalian ferritins. Biochim. Biophys. Acta 2001, 1547, 174-182. 
142. Double, K.L.; Maywald, M.; Schmittel, M.; Riederer, P.; Gerlach, M. In vitro studies of ferritin iron release and neurotoxicity. J. Neurochem. 1998, 70, 2492-2499.

143. Moser, J.C.; Rawal, M.; Wagner, B.A.; Du, J.; Cullen, J.J.; Buettner, G.R. Pharmacological ascorbate and ionizing radiation (IR) increase labile iron in pancreatic cancer. Redox Biol. 2014, 2, $22-27$.

144. Kidane, T.Z.; Sauble, E.; Linder, M.C. Release of iron from ferritin requires lysosomal activity. Am. J. Physiol. Cell Physiol. 2006, 291, C445-C455.

145. De Domenico, I.; Vaughn, M.B.; Li, L.; Bagley, D.; Musci, G.; Ward, D.M.; Kaplan, J. Ferroportin-mediated mobilization of ferritin iron precedes ferritin degradation by the proteasome. EMBO J. 2006, 25, 5396-5404.

146. Konijn, A.M.; Glickstein, H.; Vaisman, B.; Meyron-Holtz, E.G.; Slotki, I.N.; Cabantchik, Z.I. The cellular labile iron pool and intracellular ferritin in K562 cells. Blood 1999, 94, 2128-2134.

147. Truty, J.; Malpe, R.; Linder, M.C. Iron prevents ferritin turnover in hepatic cells. J. Biol. Chem. 2001, 276, 48775-48780.

148. De Domenico, I.; Ward, D.M.; Kaplan, J. Specific iron chelators determine the route of ferritin degradation. Blood 2009, 114, 4546-4551.

149. Mehlhase, J.; Sandig, G.; Pantopoulos, K.; Grune, T. Oxidation-induced ferritin turnover in microglial cells: Role of proteasome. Free Radic. Biol. Med. 2005, 38, 276-285.

150. Cozzi, A.; Santambrogio, P.; Levi, S.; Arosio, P. Iron detoxifying activity of ferritin. Effects of $\mathrm{H}$ and L human apoferritins on lipid peroxidation in vitro. FEBS Lett. 1990, 277, 119-122.

151. Levi, S.; Santambrogio, P.; Cozzi, A.; Rovida, E.; Corsi, B.; Tamborini, E.; Spada, S.; Albertini, A.; Arosio, P. The role of the L-chain in ferritin iron incorporation. Studies of homo and heteropolymers. J. Mol. Biol. 1994, 238, 649-654.

152. Arosio, P.; Levi, S. Ferritin, iron homeostasis, and oxidative damage. Free Radic. Biol. Med. 2002, 33, 457-463.

153. Chen, C.; Dewaele, S.; Braeckman, B.; Desmyter, L.; Verstraelen, J.; Borgonie, G.; Vanfleteren, J.; Contreras, R. A high-throughput screening system for genes extending life-span. Exp. Gerontol. 2003, 38, 1051-1063.

154. Tsuji, Y.; Akebi, N.; Lam, T.; Nakabeppu, Y.; Torti, S.; Torti, F. FER-1, an enhancer of the ferritin $\mathrm{H}$ gene and a target of E1A-mediated transcriptional repression. Mol. Cell. Biol. 1995, 15, 5152-5164.

155. Kwak, E.L.; Larochelle, D.A.; Beaumont, C.; Torti, S.V.; Torti, F.M. Role for NF-kappa B in the regulation of ferritin $\mathrm{H}$ by tumor necrosis factor-alpha. J. Biol. Chem. 1995, 270, 15285-15293.

156. Hintze, K.J.; Theil, E.C. DNA and mRNA elements with complementary responses to hemin, antioxidant inducers, and iron control ferritin-L expression. Proc. Natl. Acad. Sci. USA 2005, 102, $15048-15052$.

157. Tsuji, Y. JunD activates transcription of the human ferritin $\mathrm{H}$ gene through an antioxidant response element during oxidative stress. Oncogene 2005, 24, 7567-7578.

158. Pietsch, E.C.; Chan, J.Y.; Torti, F.M.; Torti, S.V. Nrf2 mediates the induction of ferritin H in response to xenobiotics and cancer chemopreventive dithiolethiones. J. Biol. Chem. 2003, 278, 2361-2369. 
159. Rogers, J.T.; Bridges, K.R.; Durmowicz, G.P.; Glass, J.; Auron, P.E.; Munro, H.N. Translational control during the acute phase response. Ferritin synthesis in response to interleukin-1. J. Biol. Chem. 1990, 265, 14572-14578.

160. Ikegami, Y.; Inukai, K.; Imai, K.; Sakamoto, Y.; Katagiri, H.; Kurihara, S.; Awata, T.; Katayama, S. Adiponectin upregulates ferritin heavy chain in skeletal muscle cells. Diabetes 2009, 58, 61-70.

161. Pham, C.G.; Bubici, C.; Zazzeroni, F.; Papa, S.; Jones, J.; Alvarez, K.; Jayawardena, S.; De Smaele, E.; Cong, R.; Beaumont, C.; et al. Ferritin heavy chain upregulation by NF-kappaB inhibits TNFalpha-induced apoptosis by suppressing reactive oxygen species. Cell 2004, 119, 529-542.

162. Pham, C.G.; Papa, S.; Bubici, C.; Zazzeroni, F.; Franzoso, G. In the crosshairs: NF-кB targets the JNK signaling cascade. Curr. Med. Chem. Anti Inflamm. Anti Allergy Agents 2005, 4, 569-576.

163. Tsuji, Y.; Miller, L.L.; Miller, S.C.; Torti, S.V.; Torti, F.M. Tumor necrosis factor-alpha and interleukin 1-alpha regulate transferrin receptor in human diploid fibroblasts. Relationship to the induction of ferritin heavy chain. J. Biol. Chem. 1991, 266, 7257-7261.

164. Miller, L.L.; Miller, S.C.; Torti, S.V.; Tsuji, Y.; Torti, F.M. Iron-independent induction of ferritin H chain by tumor necrosis factor. Proc. Natl. Acad. Sci. USA 1991, 88, 4946-4950.

165. Fahmy, M.; Young, S.P. Modulation of iron metabolism in monocyte cell line U937 by inflammatory cytokines: Changes in transferrin uptake, iron handling and ferritin mRNA. Biochem. J. 1993, 296, $175-181$.

166. Hirayama, M.; Kohgo, Y.; Kondo, H.; Shintani, N.; Fujikawa, K.; Sasaki, K.; Kato, J.; Niitsu, Y. Regulation of iron metabolism in HepG2 cells: A possible role for cytokines in the hepatic deposition of iron. Hepatology 1993, 18, 874-880.

167. Sato, H.; Yamaguchi, M.; Bannai, S. Regulation of ferritin synthesis in macrophages by oxygen and a sulfhydryl-reactive agent. Biochem. Biophys. Res. Commun. 1994, 201, 38-44.

168. Qi, Y.; Dawson, G. Hypoxia specifically and reversibly induces the synthesis of ferritin in oligodendrocytes and human oligodendrogliomas. J. Neurochem. 1994, 63, 1485-1490.

169. Torti, F.M.; Torti, S.V. Regulation of ferritin genes and protein. Blood 2002, 99, 3505-3516.

170. Faniello, M.C.; Di Sanzo, M.; Quaresima, B.; Baudi, F.; di Caro, V.; Cuda, G.; Morrone, G.; del Sal, G.; Spinelli, G.; Venuta, S.; et al. p53-Mediated downregulation of $\mathrm{H}$ ferritin promoter transcriptional efficiency via NF-Y. Int. J. Biochem. Cell Biol. 2008, 40, 2110-2119.

171. Zhang, F.; Wang, W.; Tsuji, Y.; Torti, S.V.; Torti, F.M. Post-transcriptional modulation of iron homeostasis during p53-dependent growth arrest. J. Biol. Chem. 2008, 283, 33911-33918.

172. Sammarco, M.C.; Ditch, S.; Banerjee, A.; Grabczyk, E. Ferritin L and H subunits are differentially regulated on a post-transcriptional level. J. Biol. Chem. 2008, 283, 4578-4587.

173. Tsuji, Y.; Ayaki, H.; Whitman, S.P.; Morrow, C.S.; Torti, S.V.; Torti, F.M. Coordinate transcriptional and translational regulation of ferritin in response to oxidative stress. Mol. Cell. Biol. 2000, 20, $5818-5827$.

174. Cairo, G.; Tacchini, L.; Pogliaghi, G.; Anzon, E.; Tomasi, A.; Bernelli-Zazzera, A. Induction of ferritin synthesis by oxidative stress. J. Biol. Chem. 1995, 270, 700-703.

175. Cairo, G.; Tacchini, L.; Recalcati, S.; Azzimonti, B.; Minotti, G.; Bernelli-Zazzera, A. Effect of reactive oxygen species on iron regulatory protein activity. Ann. NY Acad. Sci. 1998, 851, 179-186. 
176. Muckenthaler, M.; Richter, A.; Gunkel, N.; Riedel, D.; Polycarpou-Schwarz, M.; Hentze, S.; Falkenhahn, M.; Stremmel, W.; Ansorge, W.; Hentze, M.W. Relationships and distinctions in iron-regulatory networks responding to interrelated signals. Blood 2003, 101, 3690-3698.

177. Koorts, A.M.; Viljoen, M. Ferritin and ferritin isoforms II: Protection against uncontrolled cellular proliferation, oxidative damage and inflammatory processes. Arch. Physiol. Biochem. 2007, 113, 55-64.

178. Koc, M.; Taysi, S.; Sezen, O.; Bakan, N. Levels of some acute-phase proteins in the serum of patients with cancer during radiotherapy. Biol. Pharm. Bull. 2003, 26, 1494-1497.

179. Maria, T.G.; Vasileios, K.E.; Panagiotis, P.S.; Kostas, S.N. Changes of acute-phase protein levels in the serum of lung cancer patients following radiotherapy. Int. J. Clin. Exp. Med. 2013, 6, $50-56$.

180. Koorts, A.M.; Viljoen, M. Acute Phase Proteins: Ferritin and Ferritin Isoforms, Acute Phase Proteins-Regulation and Functions of Acute Phase Proteins. In Acute Phase Proteins-Regulation and Functions of Acute Phase Proteins; Francesco, V., Ed.; InTech: Rijeka, Croatia, 2011; pp. 153-184.

181. Breda, L.; Nozzi, M.; De Sanctis, S.; Chiarelli, F. Laboratory tests in the diagnosis and follow-up of pediatric rheumatic diseases: An update. Semin. Arthritis Rheum. 2010, 40, 53-72.

182. Rogers, J.; Lacroix, L.; Durmowitz, G.; Kasschau, K.; Andriotakis, J.; Bridges, K. The Role of Cytokines in the Regulation of Ferritin Expression. In Progress in Iron Research; Hershko, C., Konijn, A., Aisen, P., Eds.; Springer: Berlin/Heidelberg, Germany, 1994; Volume 356, pp. 127-132.

183. Ajioka, R.S.; Phillips, J.D.; Kushner, J.P. Biosynthesis of heme in mammals. Biochim. Biophys. Acta Mol. Cell Res. 2006, 1763, 723-736.

184. Wegiel, B.; Nemeth, Z.; Correa-Costa, M.; Bulmer, A.C.; Otterbein, L.E. Heme oxygenase-1: A metabolic nike. Antioxid. Redox Signal. 2013, 20, 1709-1722.

185. Soe-Lin, S.; Apte, S.S.; Andriopoulos, B.; Andrews, M.C.; Schranzhofer, M.; Kahawita, T.; Garcia-Santos, D.; Ponka, P. Nramp1 promotes efficient macrophage recycling of iron following erythrophagocytosis in vivo. Proc. Natl. Acad. Sci. USA 2009, 106, 5960-5965.

186. Soe-Lin, S.; Apte, S.S.; Mikhael, M.R.; Kayembe, L.K.; Nie, G.; Ponka, P. Both Nramp1 and DMT1 are necessary for efficient macrophage iron recycling. Exp. Hematol. 2010, 38, 609-617.

187. Seixas, E.; Gozzelino, R.; Chora, Â.; Ferreira, A.; Silva, G.; Larsen, R.; Rebelo, S.; Penido, C.; Smith, N.R.; Coutinho, A.; et al. Heme oxygenase-1 affords protection against noncerebral forms of severe malaria. Proc. Natl. Acad. Sci. USA 2009, 106, 15837-15842.

188. Larsen, R.; Gozzelino, R.; Jeney, V.; Tokaji, L.; Bozza, F.A.; Japiassu, A.M.; Bonaparte, D.; Cavalcante, M.M.; Chora, A.; Ferreira, A.; et al. A central role for free heme in the pathogenesis of severe sepsis. Sci. Transl. Med. 2010, doi:10.1126/scitranslmed.3001118.

189. Gozzelino, R.; Jeney, V.; Soares, M.P. Mechanisms of cell protection by heme oxygenase-1. Annu. Rev. Pharmacol. Toxicol. 2010, 50, 323-354.

190. Gozzelino, R.; Soares, M.P. Coupling heme and iron metabolism via ferritin H chain. Antioxid. Redox Signal. 2013, 20, 1754-1769.

191. Vile, G.F.; Basu-Modak, S.; Waltner, C.; Tyrrell, R.M. Heme oxygenase 1 mediates an adaptive response to oxidative stress in human skin fibroblasts. Proc. Natl. Acad. Sci. USA 1994, 91, $2607-2610$. 
192. Vile, G.F.; Tyrrell, R.M., Oxidative stress resulting from ultraviolet A irradiation of human skin fibroblasts leads to a heme oxygenase-dependent increase in ferritin. J. Biol. Chem. 1993, 268, 14678-14681.

193. Gozzelino, R.; Andrade, B.B.; Larsen, R.; Luz, N.F.; Vanoaica, L.; Seixas, E.; Coutinho, A.; Cardoso, S.; Rebelo, S.; Poli, M.; et al. Metabolic adaptation to tissue iron overload confers tolerance to malaria. Cell Host Microbe 2012, 12, 693-704.

194. Hamza, I.; Dailey, H.A. One ring to rule them all: Trafficking of heme and heme synthesis intermediates in the metazoans. Biochim. Biophys. Acta Mol. Cell Res. 2012, 1823, 1617-1632.

195. Lill, R.; Hoffmann, B.; Molik, S.; Pierik, A.J.; Rietzschel, N.; Stehling, O.; Uzarska, M.A.; Webert, H.; Wilbrecht, C.; Mühlenhoff, U. The role of mitochondria in cellular iron-sulfur protein biogenesis and iron metabolism. Biochim. Biophys. Acta Mol. Cell Res. 2012, 1823, 1491-1508.

196. Lill, R.; Mühlenhoff, U. Maturation of iron-sulfur proteins in eukaryotes: Mechanisms, connected processes, and diseases. Annu. Rev. Biochem. 2008, 77, 669-700.

197. Lill, R.; Mühlenhoff, U. Iron-sulfur-protein biogenesis in eukaryotes. Trends Biochem. Sci. 2005, 30, 133-141.

198. Ulvik, R.J. Ferritin iron as substrate for synthesis of protoheme in intact rat liver mitochondria. FEBS Lett. 1981, 132, 281-284.

199. Shaw, G.C.; Cope, J.J.; Li, L.; Corson, K.; Hersey, C.; Ackermann, G.E.; Gwynn, B.; Lambert, A.J.; Wingert, R.A.; Traver, D.; et al. Mitoferrin is essential for erythroid iron assimilation. Nature 2006, 440, 96-100.

200. Paradkar, P.N.; Zumbrennen, K.B.; Paw, B.H.; Ward, D.M.; Kaplan, J. Regulation of mitochondrial iron import through differential turnover of mitoferrin 1 and mitoferrin 2. Mol. Cell. Biol. 2009, 29, 1007-1016.

201. Chen, W.; Paradkar, P.N.; Li, L.; Pierce, E.L.; Langer, N.B.; Takahashi-Makise, N.; Hyde, B.B.; Shirihai, O.S.; Ward, D.M.; Kaplan, J.; et al. Abcb10 physically interacts with mitoferrin-1 (Slc25a37) to enhance its stability and function in the erythroid mitochondria. Proc. Natl. Acad. Sci. USA 2009, 106, 16263-16268.

202. Amigo, J.D.; Yu, M.; Troadec, M.-B.; Gwynn, B.; Cooney, J.D.; Lambert, A.J.; Chi, N.C.; Weiss, M.J.; Peters, L.L.; Kaplan, J.; et al. Identification of distal cis-regulatory elements at mouse mitoferrin loci using zebrafish transgenesis. Mol. Cell. Biol. 2011, 31, 1344-1356.

203. Cazzola, M.; Invernizzi, R.; Bergamaschi, G.; Levi, S.; Corsi, B.; Travaglino, E.; Rolandi, V.; Biasiotto, G.; Drysdale, J.; Arosio, P. Mitochondrial ferritin expression in erythroid cells from patients with sideroblastic anemia. Blood 2003, 101, 1996-2000.

204. Casanova-Gonzalez, M.J.; Trapero-Marugan, M.; Jones, E.A.; Moreno-Otero, R. Liver disease and erythropoietic protoporphyria: A concise review. World J. Gastroenterol. 2010, 16, 4526-4531.

205. Koeppen, A.H. Friedreich's ataxia: Pathology, pathogenesis, and molecular genetics. J. Neurol. Sci. 2011, 303, 1-12.

206. Koeppen, A.H.; Mazurkiewicz, J.E., Friedreich ataxia: Neuropathology revised. J. Neuropathol. ExpNeurol. 2013, 72, 78-90.

207. Liochev, S.I.; Fridovich, I. Superoxide and iron: Partners in crime. IUBMB Life 1999, 48, 157-161. 
208. Chen, J.; Schenker, S.; Frosto, T.A.; Henderson, G.I. Inhibition of cytochrome c oxidase activity by 4-hydroxynonenal (HNE): Role of HNE adduct formation with the enzyme subunits. Biochim. Biophys. Acta Gen. Subj. 1998, 1380, 336-344.

209. Halliwell, B.; Gutteridge, J.M.C. Biologically relevant metal ion-dependent hydroxyl radical generation An update. FEBS Lett. 1992, 307, 108-112.

210. Terman, A.; Gustafsson, B.; Brunk, U.T. Mitochondrial damage and intralysosomal degradation in cellular aging. Mol. Aspects Med. 2006, 27, 471-482.

211. Terman, A.; Gustafsson, B.; Brunk, U.T. The lysosomal-mitochondrial axis theory of postmitotic aging and cell death. Chem. Biol. Interact. 2006, 163, 29-37.

212. Kispal, G.; Csere, P.; Prohl, C.; Lill, R. The mitochondrial proteins Atm1p and Nfs1p are essential for biogenesis of cytosolic Fe/S proteins. EMBO J. 1999, 18, 3981-3989.

213. Mitsuhashi, N.; Miki, T.; Senbongi, H.; Yokoi, N.; Yano, H.; Miyazaki, M.; Nakajima, N.; Iwanaga, T.; Yokoyama, Y.; Shibata, T.; et al. MTABC3, a novel mitochondrial ATP-binding cassette protein involved in iron homeostasis. J. Biol. Chem. 2000, 275, 17536-17540.

214. Bekri, S.; Kispal, G.; Lange, H.; Fitzsimons, E.; Tolmie, J.; Lill, R.; Bishop, D.F. Human ABC7 transporter: Gene structure and mutation causing X-linked sideroblastic anemia with ataxia with disruption of cytosolic iron-sulfur protein maturation. Blood 2000, 96, 3256-3264.

215. Csere, P.; Lill, R.; Kispal, G. Identification of a human mitochondrial ABC transporter, the functional orthologue of yeast Atm1p. FEBS Lett. 1998, 441, 266-270.

216. Kispal, G.; Csere, P.; Guiard, B.; Lill, R. The ABC transporter Atm1p is required for mitochondrial iron homeostasis. FEBS Lett. 1997, 418, 346-350.

217. Koc, S.; Harris, J.W. Sideroblastic anemias: Variations on imprecision in diagnostic criteria, proposal for an extended classification of sideroblastic anemias. Am. J. Hematol. 1998, 57, 1-6.

218. Taketani, S.; Adachi, Y.; Kohno, H.; Ikehara, S.; Tokunaga, R.; Ishii, T. Molecular characterization of a newly identified heme-binding protein induced during differentiation of urine erythroleukemia cells. J. Biol. Chem. 1998, 273, 31388-31394.

219. Martelli, A.; Napierala, M.; Puccio, H. Understanding the genetic and molecular pathogenesis of Friedreich's ataxia through animal and cellular models. Dis. Model. Mech. 2012, 5, 165-176.

220. Pastore, A.; Puccio, H. Frataxin: A protein in search for a function. J. Neurochem. 2013, 126, 43-52.

221. Adamec, J.; Rusnak, F.; Owen, W.G.; Naylor, S.; Benson, L.M.; Gacy, A.M.; Isaya, G. Iron-dependent self-assembly of recombinant yeast frataxin: implications for Friedreich ataxia. Am. J. Hum. Genet. 2000, 67, 549-562.

222. Layer, G.; Ollagnier-de Choudens, S.; Sanakis, Y.; Fontecave, M. Iron-Sulfur cluster biosynthesis: characterization of Escherichia coli $\mathrm{CYaY}$ as an iron donor for the assembly of [2Fe-2S] clusters in the scaffold IscU. J. Biol. Chem. 2006, 281, 16256-16263.

223. Campuzano, V.; Montermini, L.; Molto, M.D.; Pianese, L.; Cossee, M.; Cavalcanti, F.; Monros, E.; Rodius, F.; Duclos, F.; Monticelli, A.; et al. Friedreich's ataxia: Autosomal recessive disease caused by an intronic GAA triplet repeat expansion. Science 1996, 271, 1423-1427.

224. Koutnikova, H.; Campuzano, V.; Foury, F.; Dolle, P.; Cazzalini, O.; Koenig, M. Studies of human, mouse and yeast homologues indicate a mitochondrial function for frataxin. Nat. Genet. 1997, 16, 345-351. 
225. Cossee, M.; Campuzano, V.; Koutnikova, H.; Fischbeck, K.; Mandel, J.-L.; Koenig, M.; Bidichandani, S.I.; Patel, P.I.; Molte, M.D.; Canizares, J.; et al. Frataxin fracas. Nat. Genet. 1997, 15, 337-338.

226. Campuzano, V.; Montermini, L.; Lutz, Y.; Cova, L.; Hindelang, C.; Jiralerspong, S.; Trottier, Y.; Kish, S.J.; Faucheux, B.; Trouillas, P.; et al. Frataxin is reduced in Friedreich ataxia patients and is associated with mitochondrial membranes. Hum. Mol. Genet. 1997, 6, 1771-1780.

227. Lamarche, J.B.; Cote, M.; Lemieux, B. The cardiomyopathy of Friedreich's ataxia morphological observations in 3 cases. Can. J. Neurol. Sci. 1980, 7, 389-396.

228. Rotig, A.; de Lonlay, P.; Chretien, D.; Foury, F.; Koenig, M.; Sidi, D.; Munnich, A.; Rustin, P. Aconitase and mitochondrial iron-sulphur protein deficiency in Friedreich ataxia. Nat. Genet. 1997, 17, 215-217.

229. Schmucker, S.; Martelli, A.; Colin, F.; Page, A.; Wattenhofer-Donzé, M.; Reutenauer, L.; Puccio, H. Mammalian Frataxin: An essential function for cellular viability through an interaction with a preformed ISCU/NFS1/ISD11 iron-sulfur assembly complex. PLOS ONE 2011, 6, e16199.

230. Adinolfi, S.; Iannuzzi, C.; Prischi, F.; Pastore, C.; Iametti, S.; Martin, S.R.; Bonomi, F.; Pastore, A. Bacterial frataxin CyaY is the gatekeeper of iron-sulfur cluster formation catalyzed by IscS. Nat. Struct. Mol. Biol. 2009, 16, 390-396.

231. Tsai, C.-L.; Barondeau, D.P. Human frataxin Is an Allosteric Switch That Activates the Fe-S Cluster Biosynthetic Complex. Biochemistry 2010, 49, 9132-9139.

232. Yoon, T.; Cowan, J.A. Frataxin-mediated Iron Delivery to ferrochelatase in the final step of heme biosynthesis. J. Biol. Chem. 2004, 279, 25943-25946.

233. Sellers, V.M.; Wu, C.-K.; Dailey, T.A.; Dailey, H.A. Human ferrochelatase: Characterization of Substrate-iron binding and proton-abstracting residues. Biochemistry 2001, 40, 9821-9827.

234. Wu, C.-K.; Dailey, H.A.; Rose, J.P.; Burden, A.; Sellers, V.M.; Wang, B.-C. The $2.0 \AA$ structure of human ferrochelatase, the terminal enzyme of heme biosynthesis. Nat. Struct. Mol. Biol. 2001, 8, 156-160.

235. Busi, M.V.; Gomez-Casati, D.F. Exploring frataxin function. IUBMB Life 2012, 64, 56-63.

236. Simon, D.; Seznec, H.; Gansmuller, A.; Carelle, N.; Weber, P.; Metzger, D.; Rustin, P.; Koenig, M.; Puccio, H. Friedreich ataxia mouse models with progressive cerebellar and sensory ataxia reveal autophagic neurodegeneration in dorsal root ganglia. J. Neurosci. 2004, 24, 1987-1995.

237. Kurz, T.; Terman, A.; Brunk, U.T. Autophagy, ageing and apoptosis: The role of oxidative stress and lysosomal iron. Arch. Biochem. Biophys. 2007, 462, 220-230.

238. Terman, A.; Kurz, T.; Navratil, M.; Arriaga, E.A.; Brunk, U.T. Mitochondrial turnover and aging of long-lived postmitotic cells: The mitochondrial-lysosomal axis theory of aging. Antioxid. Redox Signal. 2010, 12, 503-535.

239. Bradley, J.L.; Homayoun, S.; Hart, P.E.; Schapira, A.H.V.; Cooper, J.M. Role of oxidative damage in Friedreich's ataxia. Neurochem. Res. 2004, 29, 561-567.

240. Emond, M.; Lepage, G.; Vanasse, M.; Pandolfo, M. Increased levels of plasma malondialdehyde in Friedreich ataxia. Neurology 2000, 55, 1752-1753.

241. Schulz, J.B.; Dehmer, T.; Schöls, L.; Mende, H.; Hardt, C.; Vorgerd, M.; Bürk, K.; Matson, W.; Dichgans, J.; Beal, M.F.; et al. Oxidative stress in patients with Friedreich ataxia. Neurology 2000, 55, 1719-1721. 
242. Lefevre, S.; Sliwa, D.; Rustin, P.; Camadro, J.-M.; Santos, R. Oxidative stress induces mitochondrial fragmentation in frataxin-deficient cells. Biochem. Biophys. Res. Commun. 2012, 418, 336-341.

243. Martin, M.; Colman, M.J.R.; Gómez-Casati, D.F.; Lamattina, L.; Zabaleta, E.J. Nitric oxide accumulation is required to protect against iron-mediated oxidative stress in frataxin-deficient Arabidopsis plants. FEBS Lett. 2009, 583, 542-548.

244. Calmels, N.; Schmucker, S.; Wattenhofer-Donzé, M.; Martelli, A.; Vaucamps, N.; Reutenauer, L.; Messaddeq, N.; Bouton, C.; Koenig, M.; Puccio, H. The First cellular models based on frataxin missense mutations that reproduce spontaneously the defects associated with Friedreich ataxia. PLOS ONE 2009, 4, e6379.

245. Babcock, M.; de Silva, D.; Oaks, R.; Davis-Kaplan, S.; Jiralerspong, S.; Montermini, L.; Pandolfo, M.; Kaplan, J. Regulation of mitochondrial iron accumulation by Yfh1p, a putative homolog of frataxin. Science 1997, 276, 1709-1712.

246. Martelli, A.; Puccio, H. Dysregulation of cellular iron metabolism in Friedreich ataxia: From primary iron-sulfur cluster deficit to mitochondrial iron accumulation. Front. Pharmacol. 2014, doi:10.3389/fphar.2014.00130.

247. Afford, S.C.; Randhawa, S.; Eliopoulos, A.G.; Hubscher, S.G.; Young, L.S.; Adams, D.H. CD40 activation induces apoptosis in cultured human hepatocytes via induction of cell surface fas ligand expression and amplifies Fas-mediated hepatocyte death during allograft rejection. J. Exp. Med. 1999, 189, 441-446.

248. Seguin, A.; Sutak, R.; Bulteau, A.-L.; Garcia-Serres, R.; Oddou, J.-L.; Lefevre, S.; Santos, R.; Dancis, A.; Camadro, J.-M.; Latour, J.-M.; et al. Evidence that yeast frataxin is not an iron storage protein in vivo. Biochim. Biophys. Acta Mol. Basis Dis. 2010, 1802, 531-538.

249. Levi, S.; Corsi, B.; Bosisio, M.; Invernizzi, R.; Volz, A.; Sanford, D.; Arosio, P.; Drysdale, J. A human mitochondrial ferritin encoded by an intronless gene. J. Biol. Chem. 2001, 276, 24437-24440.

250. Gao, G.; Chang, Y.-Z. Mitochondrial ferritin in the regulation of brain iron homeostasis and neurodegenerative diseases. Front. Pharmacol. 2014, doi:10.3389/fphar.2014.00019.

251. Levi, S.; Arosio, P. Mitochondrial ferritin. Int. J. Biochem. Cell Biol. 2004, 36, 1887-1889.

252. Langlois d'Estaintot, B.; Santambrogio, P.; Granier, T.; Gallois, B.; Chevalier, J.M.; Precigoux, G.; Levi, S.; Arosio, P. Crystal structure and biochemical properties of the human mitochondrial ferritin and its mutant Ser144Ala. J. Mol. Biol. 2004, 340, 277-293.

253. Bou-Abdallah, F.; Santambrogio, P.; Levi, S.; Arosio, P.; Chasteen, N.D. Unique iron binding and oxidation properties of human mitochondrial ferritin: A comparative analysis with human H-chain ferritin. J. Mol. Biol. 2005, 347, 543-554.

254. Drysdale, J.; Arosio, P.; Invernizzi, R.; Cazzola, M.; Volz, A.; Corsi, B.; Biasiotto, G.; Levi, S. Mitochondrial ferritin: A new player in iron metabolism. Blood Cells Mol. Dis. 2002, 29, 376-383.

255. Corsi, B.; Cozzi, A.; Arosio, P.; Drysdale, J.; Santambrogio, P.; Campanella, A.; Biasiotto, G.; Albertini, A.; Levi, S. Human mitochondrial ferritin expressed in HeLa cells incorporates iron and affects cellular iron metabolism. J. Biol. Chem. 2002, 277, 22430-22437.

256. Nie, G.; Sheftel, A.D.; Kim, S.F.; Ponka, P. Overexpression of mitochondrial ferritin causes cytosolic iron depletion and changes cellular iron homeostasis. Blood 2005, 105, 2161-2167. 
257. Lu, Z.; Nie, G.; Li, Y.; Soe-Lin, S.; Tao, Y.; Cao, Y.; Zhang, Z.; Liu, N.; Ponka, P.; Zhao, B. Overexpression of mitochondrial ferritin sensitizes cells to oxidative stress via an iron-mediated mechanism. Antioxid. Redox Signal. 2009, 11, 1791-1803.

258. Santambrogio, P.; Erba, B.G.; Campanella, A.; Cozzi, A.; Causarano, V.; Cremonesi, L.; Galli, A.; Della Porta, M.G.; Invernizzi, R.; Levi, S. Overexpression of mitochondrial ferritin affects the JAK2/STAT5 pathway in K562 cells and causes mitochondria iron accumulation. Haematologica 2011, 96, 1424-1432.

259. Michael, S.; Petrocine, S.; Qian, J.; Lamarche, J.; Knutson, M.; Garrick, M.; Koeppen, A. Iron and iron-responsive proteins in the cardiomyopathy of Friedreich's ataxia. Cerebellum 2006, 5, 257-267.

260. Campanella, A.; Rovelli, E.; Santambrogio, P.; Cozzi, A.; Taroni, F.; Levi, S. Mitochondrial ferritin limits oxidative damage regulating mitochondrial iron availability: Hypothesis for a protective role in Friedreich ataxia. Hum. Mol. Genet. 2009, 18, 1-11.

261. Zanella, I.; Derosas, M.; Corrado, M.; Cocco, E.; Cavadini, P.; Biasiotto, G.; Poli, M.; Verardi, R.; Arosio, P. The effects of frataxin silencing in HeLa cells are rescued by the expression of human mitochondrial ferritin. Biochim. Biophys. Acta Mol. Basis Dis. 2008, 1782, 90-98.

262. Campanella, A.; Isaya, G.; O'Neill, H.A.; Santambrogio, P.; Cozzi, A.; Arosio, P.; Levi, S. The expression of human mitochondrial ferritin rescues respiratory function in frataxin-deficient yeast. Hum. Mol. Genet. 2004, 13, 2279-2288.

263. Sheftel, A.; Stehling, O.; Lill, R. Iron-sulfur proteins in health and disease. Trends Endocrinol. Metab. 2010, 21, 302-314.

264. Mettert, E.L.; Kiley, P.J. Fe-S proteins that regulate gene expression. Biochim. Biophys. Acta Mol. Cell Res. 2015, 1853, 1284-1293.

265. Rouault, T.A. The role of iron regulatory proteins in mammalian iron homeostasis and disease. Nat. Chem. Biol. 2006, 2, 406-414.

266. Koh, H.-J.; Lee, S.-M.; Son, B.-G.; Lee, S.-H.; Ryoo, Z.Y.; Chang, K.-T.; Park, J.-W.; Park, D.-C.; Song, B.J.; Veech, R.L.; et al. Cytosolic NADP+-dependent isocitrate dehydrogenase plays a key role in lipid metabolism. J. Biol. Chem. 2004, 279, 39968-39974.

267. Wallander, M.L.; Leibold, E.A.; Eisenstein, R.S. Molecular control of vertebrate iron homeostasis by iron regulatory proteins. Biochim. Biophys. Acta Mol. Cell Res. 2006, 1763, 668-689.

268. Walden, W.E.; Selezneva, A.I.; Dupuy, J.; Volbeda, A.; Fontecilla-Camps, J.C.; Theil, E.C.; Volz, K. Structure of dual function iron regulatory protein 1 complexed with ferritin IRE-RNA. Science 2006, 314, 1903-1908.

269. Eisenstein, R.S.; Ross, K.L. Novel roles for iron regulatory proteins in the adaptive response to iron deficiency. J. Nutr. 2003, 133, 1510S-1516S.

270. Tong, W.-H.; Rouault, T.A. Functions of mitochondrial ISCU and cytosolic ISCU in mammalian iron-sulfur cluster biogenesis and iron homeostasis. Cell Metab. 2006, 3, 199-210.

271. Pantopoulos, K.; Hentze, M.W. Rapid responses to oxidative stress mediated by iron regulatory protein. EMBO J. 1995, 14, 2917-2924.

272. Caltagirone, A.; Weiss, G.; Pantopoulos, K. Modulation of cellular iron metabolism by hydrogen peroxide: Effects of $\mathrm{H}_{2} \mathrm{O}_{2}$ on the expression and function of iron-responsive element-containing mRNAs in B6 fibroblasts. J. Biol. Chem. 2001, 276, 19738-19745. 
273. Gardner, P.R.; Raineri, I.; Epstein, L.B.; White, C.W. Superoxide radical and iron modulate aconitase activity in mammalian cells. J. Biol. Chem. 1995, 270, 13399-13405.

274. Rouault, T.A.; Klausner, R.D. Iron-sulfur clusters as biosensors of oxidants and iron. Trends Biochem. Sci. 1996, 21, 174-177.

275. Cairo, G.; Recalcati, S.; Pietrangelo, A.; Minotti, G. The iron regulatory proteins: Targets and modulators of free radical reactions and oxidative damage. Free Radic. Biol. Med. 2002, 32, 1237-1243.

276. Patel, M.; Day, B.J.; Crapo, J.D.; Fridovich, I.; McNamara, J.O. Requirement for superoxide in excitotoxic cell death. Neuron 1996, 16, 345-355.

277. Jang, S.; Imlay, J.A. Micromolar intracellular hydrogen peroxide disrupts metabolism by damaging iron-sulfur enzymes. J. Biol. Chem. 2007, 282, 929-937.

278. Flint, D.H.; Tuminello, J.F.; Emptage, M.H. The inactivation of Fe-S cluster containing hydro-lyases by superoxide. J. Biol. Chem. 1993, 268, 22369-22376.

279. Kennedy, M.C.; Emptage, M.H.; Dreyer, J.L.; Beinert, H. The role of iron in the activation-inactivation of aconitase. J. Biol. Chem. 1983, 258, 11098-11105.

280. Singh, S.P.; Niemczyk, M.; Saini, D.; Awasthi, Y.C.; Zimniak, L.; Zimniak, P. Role of the electrophilic lipid peroxidation product 4-hydroxynonenal in the development and maintenance of obesity in mice. Biochemistry 2008, 47, 3900-3911.

281. Yarian, C.S.; Rebrin, I.; Sohal, R.S. Aconitase and ATP synthase are targets of malondialdehyde modification and undergo an age-related decrease in activity in mouse heart mitochondria. Biochem. Biophys. Res. Commun. 2005, 330, 151-156.

282. McLain, A.L.; Szweda, P.A.; Szweda, L.I. alpha-Ketoglutarate dehydrogenase: A mitochondrial redox sensor. Free Radic. Res. 2011, 45, 29-36.

283. Yang, J.H.; Yang, E.S.; Park, J.W. Inactivation of $\mathrm{NADP}^{+}$-dependent isocitrate dehydrogenase by lipid peroxidation products. Free Radic. Res. 2004, 38, 241-249.

284. Lashin, O.M.; Szweda, P.A.; Szweda, L.I.; Romani, A.M.P. Decreased complex II respiration and HNE-modified SDH subunit in diabetic heart. Free Radic. Biol. Med. 2006, 40, 886-896.

285. Begriche, K.; Igoudjil, A.; Pessayre, D.; Fromenty, B. Mitochondrial dysfunction in NASH: Causes, consequences and possible means to prevent it. Mitochondrion 2006, 6, 1-28.

286. Pessayre, D.; Mansouri, A.; Haouzi, D.; Fromenty, B. Hepatotoxicity due to mitochondrial dysfunction. Cell Biol. Toxicol. 1999, 15, 367-373.

287. Liu, Q.; Simpson, D.C.; Gronert, S. Carbonylation of mitochondrial aconitase with 4-hydroxy-2(E)-nonenal: Localization and relative reactivity of addition sites. Biochim. Biophys. Acta Proteins Proteomics 2013, 1834, 1144-1154.

288. Brazzolotto, X.; Gaillard, J.; Pantopoulos, K.; Hentze, M.W.; Moulis, J.-M. Human cytoplasmic aconitase (iron regulatory protein 1 ) is converted into its [3Fe-4S] form by hydrogen peroxide in vitro but is not activated for iron-responsive element binding. J. Biol. Chem. 1999, 274, 21625-21630.

289. Pantopoulos, K.; Hentze, M.W. Activation of iron regulatory protein-1 by oxidative stress in vitro. Proc. Natl. Acad. Sci. USA 1998, 95, 10559-10563. 
290. Pantopoulos, K.; Mueller, S.; Atzberger, A.; Ansorge, W.; Stremmel, W.; Hentze, M.W. Differences in the regulation of iron regulatory protein-1 (IRP-1) by extra- and intracellular oxidative stress. J. Biol. Chem. 1997, 272, 9802-9808.

291. Brown, N.M.; Anderson, S.A.; Steffen, D.W.; Carpenter, T.B.; Kennedy, M.C.; Walden, W.E.; Eisenstein, R.S. Novel role of phosphorylation in Fe-S cluster stability revealed by phosphomimetic mutations at Ser-138 of iron regulatory protein 1. Proc. Natl. Acad. Sci. USA 1998, 95, 15235-15240.

292. Eisenstein, R.S.; Tuazon, P.T.; Schalinske, K.L.; Anderson, S.A.; Traugh, J.A. Iron-responsive element-binding protein. Phosphorylation by protein kinase C. J. Biol. Chem. 1993, 268, 27363-27370.

293. Clarke, S.L.; Vasanthakumar, A.; Anderson, S.A.; Pondarre, C.; Koh, C.M.; Deck, K.M.; Pitula, J.S.; Epstein, C.J.; Fleming, M.D.; Eisenstein, R.S. Iron-responsive degradation of iron-regulatory protein 1 does not require the Fe-S cluster. EMBO J. 2006, 25, 544-553.

294. Neonaki, M.; Graham, D.C.; White, K.N.; Bomford, A. Down-regulation of liver iron-regulatory protein 1 in haemochromatosis. Biochem. Soc. Trans. 2002, 30, 726-728.

295. Goessling, L.S.; Daniels-McQueen, S.; Bhattacharyya-Pakrasi, M.; Lin, J.J.; Thach, R.E. Enhanced degradation of the ferritin repressor protein during induction of ferritin messenger RNA translation. Science 1992, 256, 670-673.

296. Minotti, G.; Ronchi, R.; Salvatorelli, E.; Menna, P.; Cairo, G. Doxorubicin irreversibly inactivates iron regulatory proteins 1 and 2 in cardiomyocytes. Cancer Res. 2001, 61, 8422-8428.

297. Cairo, G.; Recalcati, S. Iron-regulatory proteins: Molecular biology and pathophysiological implications. Expert Rev. Mol. Med. 2007, 9, 1-13.

298. Starzyński, R.R.; Lipiński, P.; Drapier, J.-C.; Diet, A.; Smuda, E.; Bartłomiejczyk, T.; Gralak, M.A.; Kruszewski, M. Down-regulation of iron regulatory protein 1 activities and expression in superoxide dismutase 1 knock-out mice is not associated with alterations in iron metabolism. J. Biol. Chem. 2005, 280, 4207-4212.

299. Terman, A.; Kurz, T. Lysosomal iron, iron chelation, and cell death. Antioxid. Redox Signal. 2013, 18, 888-898.

300. Terman, A.; Kurz, T.; Gustafsson, B.; Brunk, U.T. Lysosomal labilization. IUBMB Life 2006, 58, 531-539.

301. McGahan, M.C.; Harned, J.; Mukunnemkeril, M.; Goralska, M.; Fleisher, L.; Ferrell, J.B. Iron alters glutamate secretion by regulating cytosolic aconitase activity. Am. J. Physiol. Cell Physiol. 2005, 288, C1117-C1124.

302. Lee, S.H.; Jo, S.H.; Lee, S.M.; Koh, H.J.; Song, H.; Park, J.W.; Lee, W.H.; Huh, T.L. Role of $\mathrm{NADP}^{+}$-dependent isocitrate dehydrogenase $\left(\mathrm{NADP}^{+}\right.$-ICDH) on cellular defence against oxidative injury by $\gamma$-rays. Int. J. Radiat. Biol. 2004, 80, 635-642.

303. Conrad, M.; Sato, H. The oxidative stress-inducible cystine/glutamate antiporter, system $\mathrm{X}_{\mathrm{c}}$ : Cystine supplier and beyond. Amino Acids 2012, 42, 231-246.

304. Lall, M.M.; Ferrell, J.; Nagar, S.; Fleisher, L.N.; McGahan, M.C. Iron regulates L-cystine uptake and glutathione levels in lens epithelial and retinal pigment epithelial cells by its effect on cytosolic aconitase. Investig. Ophthalmol. Vis. Sci. 2008, 49, 310-319.

305. Guo, B.; Yu, Y.; Leibold, E.A. Iron regulates cytoplasmic levels of a novel iron-responsive element-binding protein without aconitase activity. J. Biol. Chem. 1994, 269, 24252-24260. 
306. Samaniego, F.; Chin, J.; Iwai, K.; Rouault, T.A.; Klausner, R.D. Molecular characterization of a second iron-responsive element binding protein, iron regulatory protein 2. Structure, function, and post-translational regulation. J. Biol. Chem. 1994, 269, 30904-30910.

307. Hanson, E.S.; Foot, L.M.; Leibold, E.A. Hypoxia post-translationally activates iron-regulatory protein 2. J. Biol. Chem. 1999, 274, 5047-5052.

308. Guo, B.; Phillips, J.D.; Yu, Y.; Leibold, E.A. Iron regulates the intracellular degradation of iron regulatory protein 2 by the proteasome. J. Biol. Chem. 1995, 270, 21645-21651.

309. Iwai, K.; Drake, S.K.; Wehr, N.B.; Weissman, A.M.; LaVaute, T.; Minato, N.; Klausner, R.D.; Levine, R.L.; Rouault, T.A. Iron-dependent oxidation, ubiquitination, and degradation of iron regulatory protein 2: Implications for degradation of oxidized proteins. Proc. Natl. Acad. Sci. USA 1998, 95, 4924-4928.

310. Ke, Y.; Sierzputowska-Gracz, H.; Gdaniec, Z.; Theil, E.C. Internal loop/bulge and hairpin loop of the iron-responsive element of ferritin mRNA contribute to maximal iron regulatory protein 2 binding and translational regulation in the iso-iron-responsive element/iso-iron regulatory protein family. Biochemistry 2000, 39, 6235-6242.

311. Kim, S.; Ponka, P. Nitrogen monoxide-mediated control of ferritin synthesis: Implications for macrophage iron homeostasis. Proc. Natl. Acad. Sci. USA 2002, 99, 12214-12219.

312. Ke, Y.; Wu, J.; Leibold, E.A.; Walden, W.E.; Theil, E.C. Loops and bulge/loops in iron-responsive element isoforms influence iron regulatory protein binding. J. Biol. Chem. 1998, 273, 23637-23640.

313. Hanson, E.S.; Rawlins, M.L.; Leibold, E.A. Oxygen and iron regulation of iron regulatory protein 2. J. Biol. Chem. 2003, 278, 40337-40342.

314. Meyron-Holtz, E.G.; Ghosh, M.C.; Rouault, T.A. Mammalian tissue oxygen levels modulate iron-regulatory protein activities in vivo. Science 2004, 306, 2087-2090.

315. Chen, O.S.; Schalinske, K.L.; Eisenstein, R.S. Dietary iron intake modulates the activity of iron regulatory proteins and the abundance of ferritin and mitochondrial aconitase in rat liver. J. Nutr. 1997, 127, 238-248.

316. Schalinske, K.L.; Eisenstein, R.S. Phosphorylation and activation of both iron regulatory proteins 1 and 2 in HL-60 cells. J. Biol. Chem. 1996, 271, 7168-7176.

317. Kerenyi, M.A.; Grebien, F.; Gehart, H.; Schifrer, M.; Artaker, M.; Kovacic, B.; Beug, H.; Moriggl, R.; Müllner, E.W. Stat5 regulates cellular iron uptake of erythroid cells via IRP-2 and TfR-1. Blood 2008, 112, 3878-3888.

318. Salvatore, M.F.; Fisher, B.; Surgener, S.P.; Gerhardt, G.A.; Rouault, T. Neurochemical investigations of dopamine neuronal systems in iron-regulatory protein 2 (IRP-2) knockout mice. Mol. Brain Res. 2005, 139, 341-347.

319. Grabill, C.; Silva, A.C.; Smith, S.S.; Koretsky, A.P.; Rouault, T.A. MRI detection of ferritin iron overload and associated neuronal pathology in iron regulatory protein-2 knockout mice. Brain Res. 2003, 971, 95-106.

320. Meyron-Holtz, E.G.; Ghosh, M.C.; Iwai, K.; LaVaute, T.; Brazzolotto, X.; Berger, U.V.; Land, W.; Ollivierre-Wilson, H.; Grinberg, A.; Love, P.; et al. Genetic ablations of iron regulatory proteins 1 and 2 reveal why iron regulatory protein 2 dominates iron homeostasis. EMBO J. 2004, 23, $386-395$. 
321. Drapier, J.-C. Interplay between NO and [Fe-S] Clusters: Relevance to biological systems. Methods 1997, 11, 319-329.

322. Hausladen, A.; Fridovich, I. Superoxide and peroxynitrite inactivate aconitases, but nitric oxide does not. J. Biol. Chem. 1994, 269, 29405-29408.

323. Castro, L.; Rodriguez, M.; Radi, R. Aconitase is readily inactivated by peroxynitrite, but not by its precursor, nitric oxide. J. Biol. Chem. 1994, 269, 29409-29415.

324. Radi, R. Peroxynitrite, a Stealthy Biological Oxidant. J. Biol. Chem. 2013, 288, 26464-26472.

325. Soum, E.; Brazzolotto, X.; Goussias, C.; Bouton, C.; Moulis, J.-M.; Mattioli, T.A.; Drapier, J.-C. Peroxynitrite and nitric oxide differently target the iron-sulfur cluster and amino acid residues of human iron regulatory protein 1. Biochemistry 2003, 42, 7648-7654.

326. Kim, Y.-M.; Bergonia, H.A.; Müller, C.; Pitt, B.R.; Watkins, W.D.; Lancaster, J.R. Loss and degradation of enzyme-bound heme induced by cellular nitric oxide synthesis. J. Biol. Chem. 1995, 270, 5710-5713.

327. Hentze, M.W.; Kühn, L.C. Molecular control of vertebrate iron metabolism: mRNA-based regulatory circuits operated by iron, nitric oxide, and oxidative stress. Proc. Natl. Acad. Sci. USA 1996, 93, 8175-8182.

328. Stamler, J.S.; Singel, D.J.; Loscalzo, J. Biochemistry of nitric oxide and its redox-activated forms. Science 1992, 258, 1898-1902.

329. Watts, R.N.; Richardson, D.R. The mechanism of nitrogen monoxide (NO)-mediated iron mobilization from cells. Eur. J. Biochem. 2002, 269, 3383-3392.

330. Watts, R.N.; Richardson, D.R. Nitrogen monoxide (NO) and glucose: Unexpected links between energy metabolism and NO-mediated iron mobilization from cells. J. Biol. Chem. 2001, 276, 4724-4732.

331. Lee, M.; Arosio, P.; Cozzi, A.; Chasteen, N.D. Identification of the EPR-active iron-nitrosyl complexes in mammalian ferritins. Biochemistry 1994, 33, 3679-3687.

332. Kim, S.; Wing, S.S.; Ponka, P. S-nitrosylation of IRP2 regulates its stability via the ubiquitin-proteasome pathway. Mol. Cell. Biol. 2004, 24, 330-337.

333. Mikhael, M.; Kim, S.F.; Schranzhofer, M.; Lin, S.S.; Sheftel, A.D.; Mullner, E.W.; Ponka, P. Iron regulatory protein-independent regulation of ferritin synthesis by nitrogen monoxide. FEBS J. 2006, 273, 3828-3836.

334. Lipton, S.A.; Choi, Y.-B.; Pan, Z.-H.; Lei, S.Z.; Chen, H.-S.V.; Sucher, N.J.; Loscalzo, J.; Singel, D.J.; Stamler, J.S. A redox-based mechanism for the neuroprotective and neurodestructive effects of nitric oxide and related nitroso-compounds. Nature 1993, 364, 626-632.

335. Stamler, J.S. Redox signaling: Nitrosylation and related target interactions of nitric oxide. Cell 1994, 78, 931-936.

336. Vanin, A.F. Dinitrosyl iron complexes and S-nitrosothiols are two possible forms for stabilization and transport of nitric oxide in biological systems. Biochemistry 1998, 63, 782-793.

337. Boese, M.; Mordvintcev, P.I.; Vanin, A.F.; Busse, R.; Mülsch, A. S-nitrosation of serum albumin by dinitrosyl-iron complex. J. Biol. Chem. 1995, 270, 29244-29249.

338. Bosworth, C.A.; Toledo, J.C.; Zmijewski, J.W.; Li, Q.; Lancaster, J.R. Dinitrosyliron complexes and the mechanism(s) of cellular protein nitrosothiol formation from nitric oxide. Proc. Natl. Acad. Sci. USA 2009, 106, 4671-4676. 
339. Gaston, B.; Reilly, J.; Drazen, J.M.; Fackler, J.; Ramdev, P.; Arnelle, D.; Mullins, M.E.; Sugarbaker, D.J.; Chee, C.; Singel, D.J. Endogenous nitrogen oxides and bronchodilator S-nitrosothiols in human airways. Proc. Natl. Acad. Sci. USA 1993, 90, 10957-10961.

340. Gow, A.J.; Buerk, D.G.; Ischiropoulos, H. A novel reaction mechanism for the formation of S-nitrosothiol in vivo. J. Biol. Chem. 1997, 272, 2841-2845.

341. Hogg, N.; Singh, R.J.; Kalyanaraman, B. The role of glutathione in the transport and catabolism of nitric oxide. FEBS Lett. 1996, 382, 223-228.

342. Keszler, A.; Zhang, Y.; Hogg, N. Reaction between nitric oxide, glutathione, and oxygen in the presence and absence of protein: How are S-nitrosothiols formed? Free Radic. Biol. Med. 2010, 48, $55-64$.

343. Wink, D.A.; Nims, R.W.; Darbyshire, J.F.; Christodoulou, D.; Hanbauer, I.; Cox, G.W.; Laval, F.; Laval, J.; Cook, J.A. Reaction kinetics for nitrosation of cysteine and glutathione in aerobic nitric oxide solutions at neutral $\mathrm{pH}$. Insights into the fate and physiological effects of intermediates generated in the NO/O2 reaction. Chem. Res. Toxicol. 1994, 7, 519-525.

344. Martínez-Ruiz, A.; Lamas, S. Signalling by NO-induced protein S-nitrosylation and S-glutathionylation: Convergences and divergences. Cardiovasc. Res. 2007, 75, 220-228.

345. Rauhala, P.; Lin, A.M.-Y.; Chiueh, C.C. Neuroprotection by S-nitrosoglutathione of brain dopamine neurons from oxidative stress. FASEB J. 1998, 12, 165-173.

346. Rauhala, P.; Parameswarannay Mohanakumar, K.; Sziraki, I.; Lin, A.M.Y.; Chiueh, C.C. S-nitrosothiols and nitric oxide, but not sodium nitroprusside, protect nigrostriatal dopamine neurons against iron-induced oxidative stress in vivo. Synapse 1996, 23, 58-60.

347. Struck, A.T.; Hogg, N.; Thomas, J.P.; Kalyanaraman, B. Nitric oxide donor compounds inhibit the toxicity of oxidized low-density lipoprotein to endothelial cells. FEBS Lett. 1995, 361, 291-294.

348. Wink, D.A.; Cook, J.A.; Pacelli, R.; DeGraff, W.; Gamson, J.; Liebmann, J.; Krishna, M.C.; Mitchell, J.B. The effect of various nitric oxide-donor agents on hydrogen peroxide-mediated toxicity: A direct correlation between nitric oxide formation and protection. Arch. Biochem. Biophys. 1996, 331, 241-248.

349. Chiueh, C.C.; Rauhala, P. The redox pathway of S-nitrosoglutathione, glutathione and nitric oxide in cell to neuron communications. Free Radic. Res. 1999, 31, 641-650.

350. Chiueh, C.C. Neuroprotective Properties of Nitric Oxide. Ann. NY Acad. Sci. 1999, 890, 301-311.

351. Meloche, B.A.; O'Brien, P.J. S-nitrosyl glutathione-mediated hepatocyte cytotoxicity. Xenobiotica 1993, 23, 863-871.

352. Kim, S.; Ponka, P. Effects of interferon- $\gamma$ and lipopolysaccharide on macrophage iron metabolism are mediated by nitric oxide-induced degradation of iron regulatory protein 2. J. Biol. Chem. 2000, 275, 6220-6226.

353. Kim, S.; Ponka, P. Control of transferrin receptor expression via nitric oxide-mediated modulation of iron-regulatory protein 2. J. Biol. Chem. 1999, 274, 33035-33042.

354. Kennedy, M.C.; Antholine, W.E.; Beinert, H. An EPR Investigation of the products of the reaction of cytosolic and mitochondrial aconitases with nitric oxide. J. Biol. Chem. 1997, 272, 20340-20347.

355. Bouton, C.; Raveau, M.; Drapier, J.-C. Modulation of Iron regulatory protein functions. J. Biol. Chem. 1996, 271, 2300-2306. 
356. Drapier, J.C.; Hirling, H.; Wietzerbin, J.; Kaldy, P.; Kuhn, L.C. Biosynthesis of nitric oxide activates iron regulatory factor in macrophages. EMBO J. 1993, 12, 3643-3649.

357. Recalcati, S.; Taramelli, D.; Conte, D.; Cairo, G. Nitric oxide-mediated induction of ferritin synthesis in j774 macrophages by inflammatory cytokines: Role of selective iron regulatory protein-2 downregulation. Blood 1998, 91, 1059-1066.

358. Pantopoulos, K. Iron Metabolism and the IRE/IRP regulatory system: An update. Ann. NY Acad. Sci. 2004, 1012, 1-13.

359. Pantopoulos, K.; Weiss, G.; Hentze, M.W. Nitric oxide and oxidative stress $\left(\mathrm{H}_{2} \mathrm{O}_{2}\right)$ control mammalian iron metabolism by different pathways. Mol. Cell. Biol. 1996, 16, 3781-3788.

360. Mulero, V.; Brock, J.H. Regulation of Iron Metabolism in Murine J774 Macrophages: Role of nitric oxide-dependent and -independent pathways following activation with gamma interferon and lipopolysaccharide. Blood 1999, 94, 2383-2389.

361. Weiss, G.; Goossen, B.; Doppler, W.; Fuchs, D.; Pantopoulos, K.; Werner-Felmayer, G.; Wachter, H.; Hentze, M.W. Translational regulation via iron-responsive elements by the nitric oxide/NO-synthase pathway. EMBO J. 1993, 12, 3651-3657.

362. Wang, J.; Chen, G.; Pantopoulos, K. Nitric oxide inhibits the degradation of IRP2. Mol. Cell. Biol. 2005, 25, 1347-1353.

363. Weiss, G.; Werner-Felmayer, G.; Werner, E.R.; Grünewald, K.; Wachter, H.; Hentze, M.W. Iron regulates nitric oxide synthase activity by controlling nuclear transcription. J. Exp. Med. 1994, 180, 969-976.

364. Hibbs, J.B., Jr.; Taintor, R.R.; Vavrin, Z. Iron depletion: Possible cause of tumor cell cytotoxicity induced by activated macrophages. Biochem. Biophys. Res. Commun. 1984, 123, 716-723.

365. Richardson, D.R.; Ponka, P. The molecular mechanisms of the metabolism and transport of iron in normal and neoplastic cells. Biochim. Biophys. Acta 1997, 1331, 1-40.

366. Wilkinson, N.; Pantopoulos, K. The IRP/IRE system in vivo: Insights from mouse models. Front. Pharmacol. 2014, doi:10.3389/fphar.2014.00176.

367. Ghosh, M.C.; Zhang, D.-L.; Jeong, S.Y.; Kovtunovych, G.; Ollivierre-Wilson, H.; Noguchi, A.; Tu, T.; Senecal, T.; Robinson, G.; Crooks, D.R.; et al. Deletion of iron regulatory protein 1 causes polycythemia and pulmonary hypertension in mice through translational de-repression of HIF2 $\alpha$. Cell Metab. 2013, 17, 271-281.

368. Kapitsinou, P.P.; Liu, Q.; Unger, T.L.; Rha, J.; Davidoff, O.; Keith, B.; Epstein, J.A.; Moores, S.L.; Erickson-Miller, C.L.; Haase, V.H. Hepatic HIF-2 regulates erythropoietic responses to hypoxia in renal anemia. Blood 2010, 116, 3039-3048.

369. Ganz, T. Systemic iron homeostasis. Physiol. Rev. 2013, 93, 1721-1741.

370. Liu, Q.; Davidoff, O.; Niss, K.; Haase, V.H. Hypoxia-inducible factor regulates hepcidin via erythropoietin-induced erythropoiesis. J. Clin. Invest. 2012, 122, 4635-4644.

371. Mastrogiannaki, M.; Matak, P.; Mathieu, J.R.R.; Delga, S.; Mayeux, P.; Vaulont, S.; Peyssonnaux, C. Hepatic hypoxia-inducible factor-2 down-regulates hepcidin expression in mice through an erythropoietin-mediated increase in erythropoiesis. Haematologica 2012, 97, 827-834.

372. Wilkinson, N.; Pantopoulos, K. IRP1 regulates erythropoiesis and systemic iron homeostasis by controlling HIF2 $\alpha$ mRNA translation. Blood 2013, 122,1658-1668. 
373. Taylor, M.; Qu, A.; Anderson, E.R.; Matsubara, T.; Martin, A.; Gonzalez, F.J.; Shah, Y.M. Hypoxia-Inducible factor- $2 \alpha$ mediates the adaptive increase of intestinal ferroportin during iron deficiency in mice. Gastroenterology 2011, 140, 2044-2055.

374. Mastrogiannaki, M.; Matak, P.; Keith, B.; Simon, M.C.; Vaulont, S.; Peyssonnaux, C. HIF-2 $\alpha$, but not HIF-1 $\alpha$, promotes iron absorption in mice. J. Clin. Invest. 2009, 119, 1159-1166.

375. Shah, Y.M.; Matsubara, T.; Ito, S.; Yim, S.-H.; Gonzalez, F.J. Intestinal hypoxia inducible transcription factors are essential for iron absorption following iron deficiency. Cell Metab. 2009, 9, 152-164.

376. Keith, B.; Johnson, R.S.; Simon, M.C. HIF1 $\alpha$ and HIF2 $\alpha$ : Sibling rivalry in hypoxic tumour growth and progression. Nat. Rev. Cancer 2012, 12, 9-22.

377. Li, Z.; Rich, J. Hypoxia and Hypoxia Inducible Factors in Cancer Stem Cell Maintenance. In Diverse Effects of Hypoxia on Tumor Progression; Simon, M.C., Ed.; Springer: Berlin/Heidelberg, Germany, 2010; Volume 345, pp. 21-30.

378. Wang, W.; Deng, Z.; Hatcher, H.; Miller, L.D.; Di, X.; Tesfay, L.; Sui, G.; D’Agostino, R.B.; Torti, F.M.; Torti, S.V. IRP2 regulates breast tumor growth. Cancer Res. 2014, 74, 497-507.

379. Wu, K.-J.; Polack, A.; Dalla-Favera, R. Coordinated regulation of iron-controlling genes, H-Ferritin and IRP2, by c-MYC. Science 1999, 283, 676-679.

380. Torti, S.V.; Torti, F.M. Iron and cancer: More ore to be mined. Nat. Rev. Cancer 2013, 13, $342-355$.

381. Templeton, D.M.; Liu, Y. Genetic regulation of cell function in response to iron overload or chelation. Biochim. Biophys. Acta Gen. Subj. 2003, 1619, 113-124.

382. Wesselius, L.J.; Nelson, M.E.; Skikne, B.S. Increased release of ferritin and iron by iron-loaded alveolar macrophages in cigarette smokers. Am. J. Respir. Crit. Care Med. 1994, 150, 690-695.

383. Bresgen, N.; Ohlenschlager, I.; Wacht, N.; Afazel, S.; Ladurner, G.; Eckl, P.M. Ferritin and FasL (CD95L) mediate density dependent apoptosis in primary rat hepatocytes. J. Cell. Physiol. 2008, 217, 800-808.

384. Bresgen, N.; Rolinek, R.; Hochleitner, E.; Lottspeich, F.; Eckl, P.M. Induction of apoptosis by a hepatocyte conditioned medium. J. Cell. Physiol. 2004, 198, 452-460.

(C) 2015 by the authors; licensee MDPI, Basel, Switzerland. This article is an open access article distributed under the terms and conditions of the Creative Commons Attribution license (http://creativecommons.org/licenses/by/4.0/). 